\title{
Improving Thermal Comfort of Low-Income Housing in Thailand through Passive Design Strategies
}

\author{
Nafisa Bhikhoo $^{1, *}$, Arman Hashemi ${ }^{2,3}$ (D) and Heather Cruickshank ${ }^{3}$ \\ 1 Department of Engineering, University of Cambridge, Cambridge CB2 1PZ, UK \\ 2 School of Environment and Technology, University of Brighton, Brighton BN2 4GJ, UK; \\ a.hashemi@brighton.ac.uk \\ 3 Centre for Sustainable Development, Department of Engineering, University of Cambridge, \\ Cambridge CB2 1PZ, UK; hjcruickshank@gmail.com \\ * Correspondence: nafisabhikhoo@gmail.com; Tel.: +27-796-504-785
}

Received: 30 June 2017; Accepted: 10 August 2017; Published: 15 August 2017

\begin{abstract}
In Thailand, the delivery of adequate low-income housing has historically been overshadowed by politics with cost and quantity being prioritised over quality, comfort and resilience. In a country that experiences hot and humid temperatures throughout the year, buildings need to be adaptable to the climate to improve the thermal comfort of inhabitants. This research is focused on identifying areas for improving the thermal performance of these housing designs. Firstly, dynamic thermal simulations were run on a baseline model using the adaptive thermal comfort model CIBSE TM52 for assessment. The three criteria defined in CIBSE TM52 were used to assess the frequency and severity of overheating in the buildings. The internal temperature of the apartments was shown to exceed the thermal comfort threshold for these criteria throughout the year. The internal operating daily temperatures of the apartment remain high, ranging from a maximum of $38.5^{\circ} \mathrm{C}$ to a minimum of $27.3^{\circ} \mathrm{C}$. Based on these findings, five criteria were selected to be analysed for sensitivity to obtain the key parameters that influence the thermal performance and to suggest possible areas for improvement. The computer software package Integrated Environmental Solutions-Virtual Environment (IES-VE) was used to perform building energy simulations. Once the baseline conditions were identified, the software packages SimLab2.2 and RStudio were used to carry out the sensitivity analysis. These results indicated that roof material and the presence of a balcony have the greatest influence on the system. Incorporating insulation into the roof reduced the mean number of days of overheating by $21.43 \%$. Removing the balcony increased the number of days of overheating by $19.94 \%$ due to significant reductions in internal ventilation.
\end{abstract}

Keywords: thermal comfort; low income housing; Thailand; tropical climates; dynamic thermal simulations; sensitivity analysis

\section{Introduction}

The consequences of rapid urbanization and the growing disparities in wealth between residents in the developing world have brought the issue surrounding the sustainability of low income housing to the forefront. The correlations between population growth, climate change and energy efficiency in housing in these regions indicate that priorities need to be placed on planned future development $[1,2]$. The accessibility of affordable housing is limited by the socio-economic status of those who need it [3] and the quality of the current stock of low income housing is characterised by technical inefficiencies and inappropriate design elements thus rendering it inadequate for day to day living. With concerns growing over urban liveability in these regions, priorities need to be placed on planned future development [2]. This involves a shift towards the provision of housing that not only make use 
of environmentally sensitive construction materials, processes and technologies, but also considers how housing performs under the effects of both internal and external climatic factors [1].

In Thailand, low and middle income housing is provided by the government [4]. However, delivery of adequate housing has historically been overshadowed by politics with cost and quantity being prioritised over quality, comfort and resilience [5]. In a country that experiences hot and humid temperatures throughout the year, buildings need to be adaptable to the climate in order to improve the thermal comfort of inhabitants. Extensive research has been done to address energy and thermal comfort issues in developed countries for domestic and non-domestic building. Less research has been done to evaluate and address overheating and thermal discomfort in low-income tropical housing. This research aims to address this by evaluating and suggesting solutions to improve thermal comfort in low-income housing in Thailand.

In trying to overcome challenges of demand and to optimise land usage, low income housing designs in tropical regions were produced and are continuing to be produced according to western standards [3]. An example of the continued implementation of capital intensive methods of "providing large-scale housing to as many people as possible" [3] in Thailand, is the Baan Ua-Arthorn project in Bangkok. Under the Baan Ua-Arthorn programme, roughly $71 \%$ of the houses built were low-rise condominiums. The average construction cost of one of these low income condominiums equates to 8000 THB per $\mathrm{m}^{2}$ [6]. Due to the low cost nature of these housing estates, the units are characterised by their use of inadequate materials [7], the inferior quality of the design and the construction, and located in hard to reach urban zones [8]. While the Baan Ua-Arthorn housing programme was discontinued and replaced with preferred bottom-up or "community-based development" [8] initiatives, the programme highlights the concern over sustainable housing standards for the poorer sectors of society.

The attributes of housing in Thailand are progressively changing due to advances in the socio-economic situations of individuals and the social aspirations attributed to development $[9,10]$. Figure 1 shows the trend of increased dependency on mechanical forms of cooling within urban areas of Thailand. The incorporation of architectural specifications for housing which are incompatible with both the prevailing climatic conditions is found to exacerbate issues associated with extreme indoor temperatures and comfort, adequate natural ventilation and low levels of indoor air quality in these dwellings [11]. Rapid urbanization has also played a part in the influence of elevated temperatures in these dwellings. Sprawling urban structure and high building density in urban centres such as Bangkok have been found to exacerbate the urban heat island effect (UHI) by decreasing air velocity and increasing air temperatures of the urban climate [12,13]. This has induced a dependency on mechanical forms of cooling once individuals can afford it [14] and the residential energy consumption in Thailand set to increase more than twofold by 2030 [6]. The construction of housing that can adapt to dominant climatic conditions is a key element of providing appropriately sustainable housing and reducing energy consumption in an urban context [2].
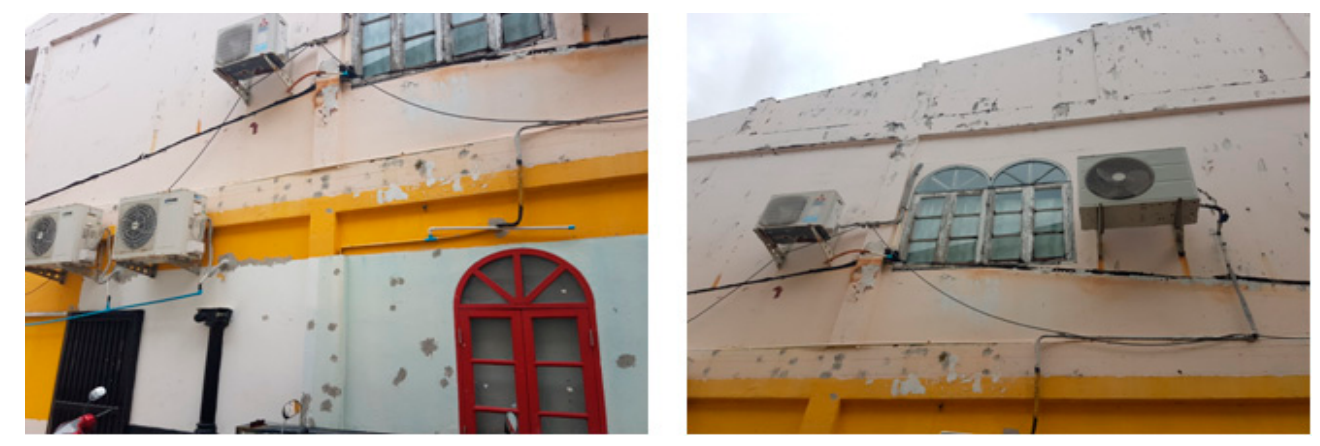

Figure 1. Air conditioning units arranged on low income housing units in Phuket, Thailand.

According to the Köppen Climate Classification [15], the tropics fall within $15^{\circ}$ north and south of the Equator and are characterised by annual air temperature above $18{ }^{\circ} \mathrm{C}\left(64^{\circ} \mathrm{F}\right)$ and the lack 
of definitive thermal seasonal changes. The temperature ranges between day and night tend to be greater than those experienced between the summer and the winter months. Three variable climatic zones exist within the tropics itself, based on the distinctions experienced in the temperature and precipitation patterns. These are classified as Type A climates and includes the: wet equatorial climate (Af), the tropical monsoon and trade-wind littoral climate (Am) and the tropical wet-dry climate (Aw).

Thailand falls within the tropical wet-dry climate (Aw) characterised by hot and humid conditions throughout the year $[10,16]$. Three distinct climatic periods with the hottest temperatures experienced from March to May, the rainy season consisting of elevated levels of relative humidity occurs from June to October and a relatively colder period occurs from November to February [14]. The mean daily temperature ranges $26-36^{\circ} \mathrm{C}$ with the average minimum temperature falling to $21^{\circ} \mathrm{C}$ in the "winter" months with the annual average temperature reaching $28^{\circ} \mathrm{C}$ [10]. The relative humidity remains high throughout the year averaging $74-85 \%$ and peaking during the rainy months. Daytime temperatures are found to exceed those temperatures deemed thermally comfortable throughout the year [6].

Traditional steady-state thermal comfort models have been found to disregard how people adapt to their environments by changing the conditions to become more accommodating [17-19]. This is of particular concern in hot and humid tropical climates as the application of these thermal comfort indices has been shown to inadequately predict levels of thermal comfort in these regions $[7,10,20,21]$. In the tropics, people have adapted to being comfortable at higher temperatures for longer periods of time [21]. In Thailand, field studies have shown that in naturally ventilated buildings, individuals remain a state of reasonable comfort at $28^{\circ} \mathrm{C}$ [22] with an upper limit for thermal comfort reaching $31.5^{\circ} \mathrm{C}[10]$.

The combination of building physics principles and climate is confirmed as an important factor in low income housing design, with inefficient building performance elevating already heightened indoor temperatures and thus impacting on thermal comfort of the inhabitants of these houses [11,23]. The distinct nature of the Thai climate means that housing design in these regions needs to incorporate strategies that exploit the benefits from the outdoor climate to achieve thermal comfort inside [24]. Passive design strategies have been proposed as an adequate method to achieve optimum indoor environmental conditions in residential buildings and thus reduce energy consumption in numerous tropical regions. The main design consideration is incorporating elements that minimise internal heat gains and maintain thermal comfort of inhabitants during periods of high solar radiation and relative humidity. Various studies have been conducted on the types of passive design features that induce improved thermal comfort in tropical regions [20,25-28].

In tropical climates, sufficient air movement through buildings has the capacity to reduce thermal discomfort. The high outdoor temperatures and elevated levels of relative humidity mean that indoor comfort is promoted through both the number of air exchanges that occur as well as the speed of the air [29] Studies have shown that air movement of up to $1 \mathrm{~m} / \mathrm{s}$ can reduce internal operating temperatures by $3.5^{\circ} \mathrm{C}[10,21]$.

To take advantage of ventilation cooling strategies, the distribution, size and number of openings needs to be maximised. Openings in each room are critical to aid in the airflow. The internal layout should be designed to allow for airflow through principal rooms and from the front to the back of the building [30]. The incorporation of balconies induces the free movement of air into tropical housing designs have been found to accelerate airflow into a dwelling [29]. A balcony acts like a "wind scoop" enhancing the rate of air movement through its opening [29].

Stack ventilation is a common form of heat dissipation that uses physical concepts of air density or the stack-effect to drive warm air upwards. The incorporation of a solar chimney on the roof removes the warm, humid air and entrains cooler air into the internal environment. These design parameters have been found to increase the rate of natural ventilation in areas with limited wind speeds [11].

In tropical regions, nighttime temperatures remain relatively high. This makes night cooling of buildings a challenge. The utilisation of ventilation and heat diffusion techniques can help compensate for this climatic restriction and assist in the reduction of internal operating temperatures at night [6]. 
Radiant gains from sun exposure and conduction gains through the building envelope account for $80 \%$ and $20 \%$ of external heat gains in tropical climates respectively [30]. Passive design means incorporating efficient mechanisms of solar protection to reduce direct solar exposure. The strategy is to optimise the effects of shading by orientating openings with overhangs (horizontal shades) to the north or south to maximise shading when the sun is at its peak. This provides optimum shading of windows and walls over the year [6]. Vertical shading elements should be used on the east and west facing openings to obstruct direct sunlight.

The thermal characteristics of materials have a significant influence on the induction of passive cooling in buildings. The optimisation of materials with high thermal resistance (low U-values) means that the building envelope will have greater insulating properties, thereby reducing conduction heat into a dwelling. Thermal insulation in the roof and the walls induces the same effects by reducing the heat gain through the structural elements. Conversely, the insulation will restrict heat loss from the interior space at night creating discomfort [6]. Materials with high surface emissivity can easily absorb and release radiant heat which could also induce discomfort [31]. The utilisation of materials with low thermal storage capacities are optimum for improving the thermal comfort at night as they cool down rapidly $[6,23]$.

The purpose of a sensitivity analysis (SA) is to ascertain how the uncertainty associated with the individual inputs into a model affects the uncertainty of the outputs of the model [32]. Passive design parameters can be screened in order to identify the main factors that have an effect on a desired outcome or system. This involves establishing the critical factors and not the interaction between the factors. The applications of SA techniques are useful for assessing thermal responses of building and data variability [33]. This paper describes the process of using a sensitivity analysis in order to assess an array of passive design parameters and their specific effects on the thermal performance on a case study building. Recommendations on the use of these passive design features can then be made.

The Energy and Low Income Tropical Housing programme is structured to look at elements of sustainable design that alleviate energy dependency in both these areas. This study serves as a component of the continued research into identifying low cost methods of improving thermal comfort through passive design techniques, less energy intensive building materials and adaptive construction techniques in tropical regions. Under the long-term outcomes of the ELITH project, this study aims to analyse elements of the building envelope that influence building performance and thereby make recommendations on viable options to solve the inadequacies. The first objective from this research is to develop a detailed analysis on the performance of key design and material elements of government provided low income housing in order to understand contextual aspects of thermal comfort and cooling. The second objective involves assessing the sensitivity of these elements using representative passive design parameters to understand the use of passive design techniques as a low cost design strategy for more sustainable housing supply. Finally, this research aims to make recommendations based on the adequacy of the design strategies in Naturally Ventilated Buildings (NVB) in consideration of the Thai context.

\section{Methodology}

The methodological approach to answering the research objectives incorporates the use of energy modelling software to obtain data about the thermal performance of a "typical" housing unit in Thailand. The primary processes involved in this study include:

- Establish a housing design to be used as a baseline example for assessment.

- Identify material compositions and geometric design aspects of the condominium housing models.

- Generate a 3-D model incorporating construction and thermal properties of the condominium housing models in IES VE.

- Carry out building energy simulations for the standard housing design using IES-VE software (Integrated Environmental Solutions, Glasgow, United Kingdom). 
- Validate the results of the thermal performance of the baseline model according to adaptive thermal comfort standards.

- Identify passive design techniques in the form of key material and design parameters that influence thermal comfort in low income housing in tropical regions.

- Develop permutations of design parameters using SimLab2.2 Sensitivity Analysis Software (Joint Research Centre - European Commission, Brussels, Belgium).

- Run building energy simulations incorporating of the permutations of the standard baseline housing model that incorporate the various design and material changes in IES VE software.

- Compare the results to those obtained for the baseline model in order to assess variances in the thermal performance of the housing model.

- Identify the parameters that have the most effect on the thermal performance.

- Undertake a sensitivity analysis based on the results of running simulations for each permutation using SimLab2.2 Sensitivity Analysis and RStudio statistical software (Allaire Corporation, Newton, MA, USA).

Dynamic Thermal Simulations (DTS) were conducted in IES VE in order to obtain data about the thermal performance of a "typical" housing unit in Thailand. The virtual environment was established using the daily temperature over a twelve-month period for the Bangkok Metropolis $\left(13.73^{\circ} \mathrm{N}\right.$, $100.57^{\circ} \mathrm{E}$ ). This included the Dry Bulb temperature and the Daily Running Mean Temperature from the 1st of January to the 31st December. The model was set up in order to assess the performance of the dwelling under the "worst case scenario" conditions for the south facing case study building. It should be noted that, in areas close to the equator, the sun is high in the sky and east/west orientation may represent the worst case scenario [34].

The Baan Ua-Arthorn housing programme was selected for analysis due to its status as a pioneering governmental approach to deliver one million affordable homes for urban citizens in five years [8]. During the eight years of implementation of this programme, the government delivered a total of 253,164 housing units of which 186,507 were condominiums [5]. Statistics show that an average Thai household consists of four individuals [35], thus each level of the apartment block was reduced to a representative five zone layout of $33 \mathrm{~m}^{2}$ with four occupants. The bedroom is the only room with an outside facing window, while the kitchen and the living room both contain windows overlooking the internal hallway. The layout of a single level is shown in Figure 2. The hallway is $36 \mathrm{~m}$ long with a stairwell at one end connecting each of the levels. Each floor contains six apartments. The hallway contains two windows at one end closest to the stairwell.

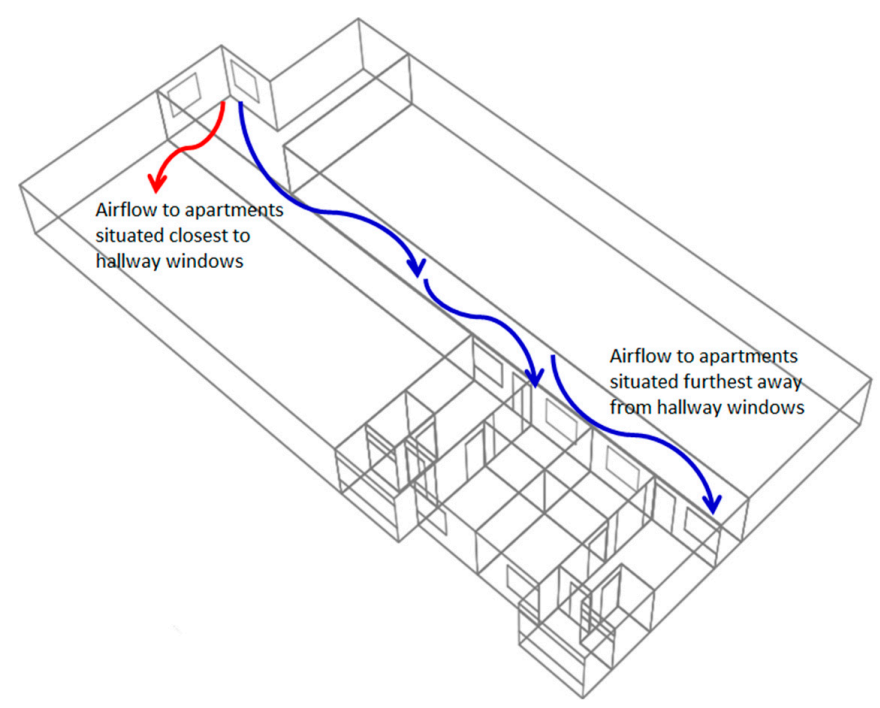

Figure 2. Plan layout of individual apartment with floor area of rooms. 
The windows are set at dimensions of $1.5 \mathrm{~m} \times 1.5 \mathrm{~m}$ and are situated $1 \mathrm{~m}$ above the base. The doors are set at $0.9 \mathrm{~m} \times 2.5 \mathrm{~m}$. Figure 3 shows the basic plan layout of one of the apartments including the dimensions of the windows and doors.

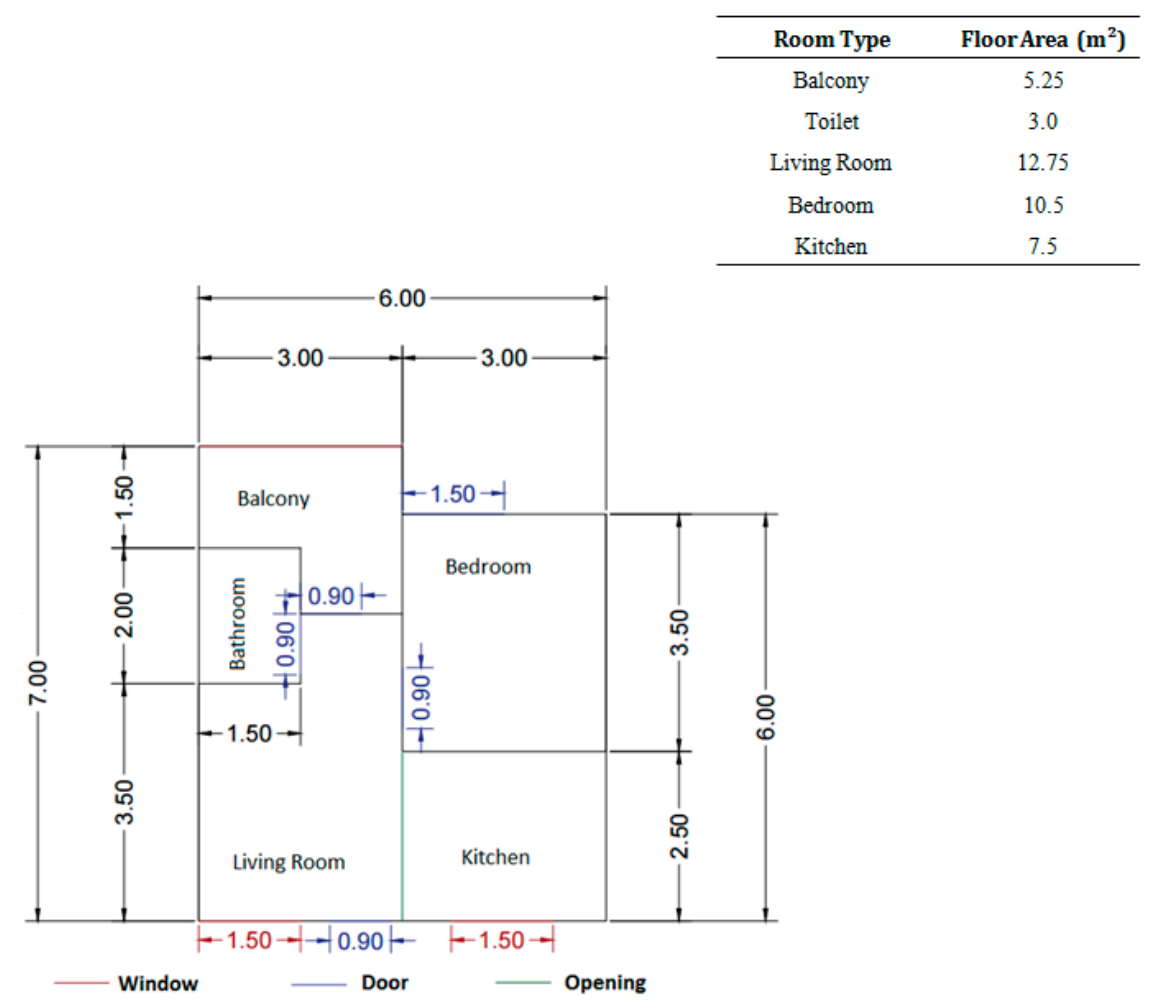

Figure 3. Plan layout of individual apartment with floor area of rooms.

The house windows are all defined as louvre windows (Figure 4) with window openable area at $25 \%$. The openable area for the doors was set to $50 \%$.

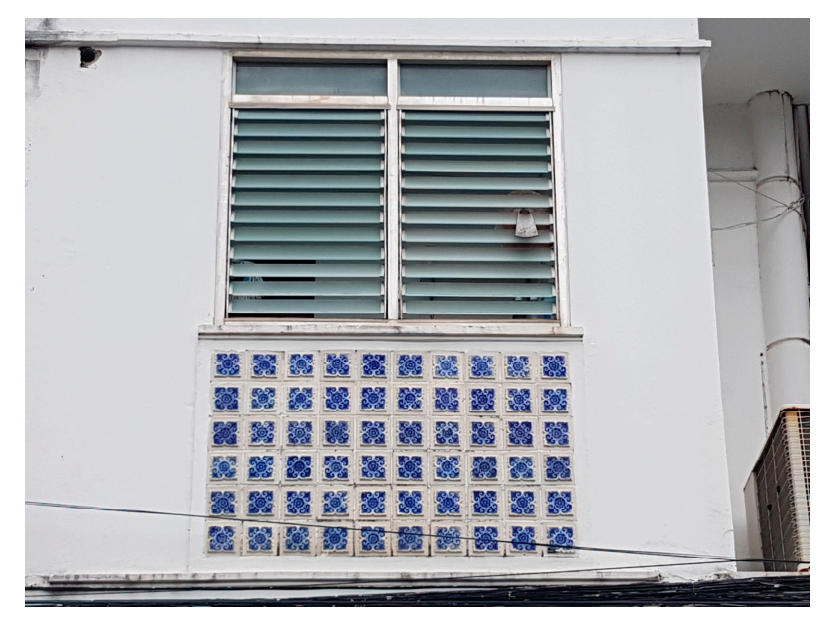

Figure 4. Typical example of louvre windows used for housing developments in urban areas of Thailand.

The balcony was modelled as a window that is continuously open at $100 \%$. Figure 5 shows the location of the balcony in proximity to the bedroom. The balustrade of the balcony is composed of clay brick and cement. 


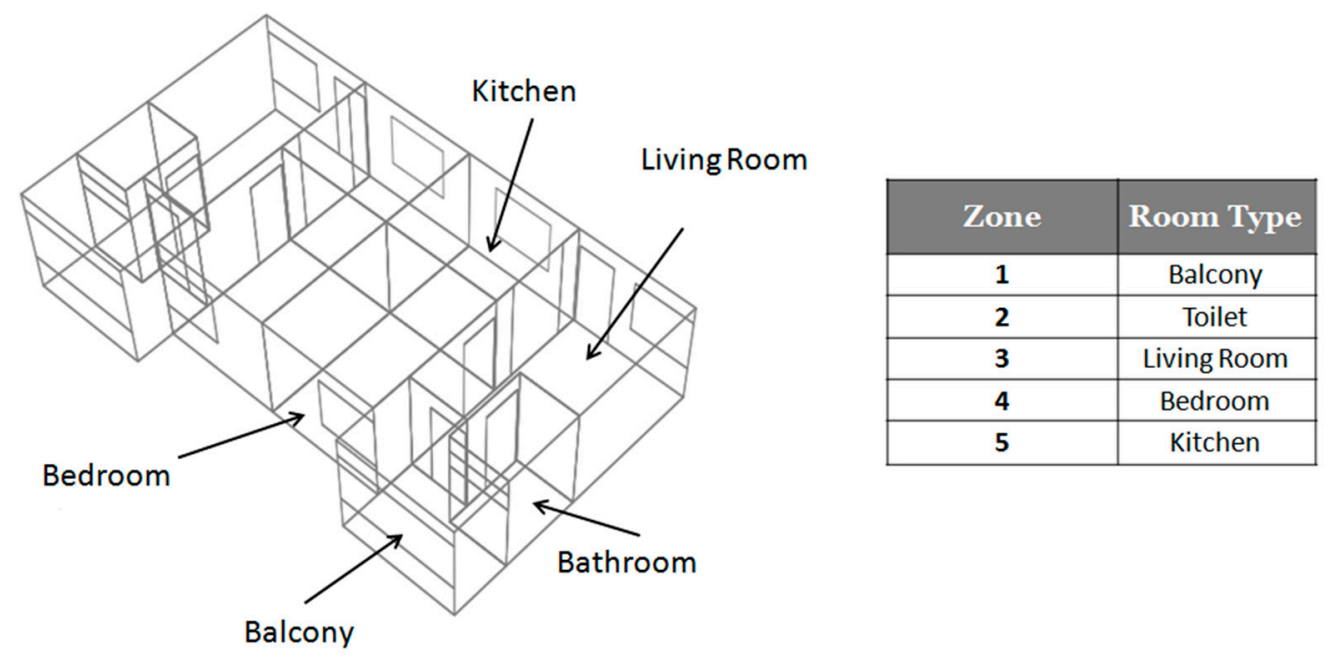

Figure 5. Isometric layout of typical apartment layout with zone classification.

For the basis of this research the buildings are considered as naturally ventilated with no forms of mechanical cooling due to the socio-economic status of the home owners [6]. The number of air exchanges per room was set to $4 \mathrm{ac} / \mathrm{h}$ to account for the lower quality standards of the condominiums considering the low income context [8].

According to the Bill of Quantities (BOQ), the standard method of construction for housing under the Baan Ua-Arthorn Housing project included a skeleton composed of reinforced concrete columns and beams for structural stability and infill brickwork walls for the bracing [6]. Table 1 summarises the type and characteristics of the materials used in an individual five-storey apartment block.

Table 1. Material description of typical housing unit [36].

\begin{tabular}{cccc}
\hline Material & $\begin{array}{c}\text { Thermal Conductivity } \\
(\mathbf{W} / \mathbf{m} \cdot \mathbf{K})\end{array}$ & Thickness (m) & Surface Emissivity \\
\hline Roof tiles & 6.266 & $5 \mathrm{~mm}$ & 0.51 \\
External Walls Clay brick and & 2.246 & $200 \mathrm{~mm}$ & 0.75 \\
cement rendering & 3.384 & $100 \mathrm{~mm}$ & 0.90 \\
Internal Partitions Concrete Block & 2.7465 & $6 \mathrm{~mm}$ & 0.90 \\
Windows glazing & 1.255 & $90 \mathrm{~mm}$ & 0.85 \\
Ceiling Gypsum & 3.618 & $250 \mathrm{~mm}$ & 0.90 \\
Floor Reinforced concrete &
\end{tabular}

The occupancy profile of the case study building has been specified as fully occupied 20:00-6:00 and on weekends, with working hours spanning 6:00-20:00. The schedule of openings for the baseline model was created on the basis that windows are all open during the day and closed during the night. The simulations for the study are split into two parts, namely Section A: Thermal performance of the baseline model (Table 2); and Section B: The sensitivity analysis for passive design features.

\subsection{Section A}

Section A details the generation of a 3-D model incorporating construction and thermal properties of the condominium models in IES VE. This includes the validation of the results of the thermal performance of the baseline model according to adaptive thermal comfort standards.

IES Virtual Environment is a software package created by Integrated Environmental Solutions that is used for building energy analysis and sustainable design. IES-VE consists of a range of built-in analysis tools, which facilitate the ease of modelling and analysing the performance of a building either retrospectively or during the design stages of a construction project. The interface makes use of 
a graphical user interface (GUI) or "black box", which produces graphical results based on a series of user specified inputs. For the purpose of this study the ease of the interface and geometry building, the speed with which results can be produced and the scale of the models needed to be simulated makes it ideal.

The adaptive thermal comfort standard chosen for assessment in this study was CIBSE with the specific guideline CIBSE TM52. Table 2 shows the summary of the conditions chosen for the baseline model. The performance of the baseline model has been studied by reporting the risk of overheating.

Table 2. Summary of conditions specified for baseline model analysis using IES VE.

\begin{tabular}{cc}
\hline Specified Condition & Baseline Model Settings \\
\hline Simulation Period & 12 months \\
Weather Data & Bangkok, Thailand \\
Occupants & 4 occupants with internal gains of $90 \mathrm{~W} /$ person $/$ day \\
Occupancy patterns & 20:00-6:00 working days, occupied all other times \\
Internal Gains & Gas cooking stove $106 \mathrm{~W} / \mathrm{m}^{2}$, lighting $8 \mathrm{~W} / \mathrm{m}^{2}$ \\
\hline
\end{tabular}

Adaptive approach has been used to assess thermal comfort conditions for the baseline model. Thermal comfort in adaptive approach is affected by occupants' behaviours and expectations in naturally ventilated buildings [37]. Based on this method of evaluation, it is proposed that occupants' perception regarding thermal comfort is affected by their thermal circumstances [21]. For typical occupants, CEN standard BS EN 15,251 [38] suggests the following equation to estimate comfortable temperature in naturally ventilated buildings (Equation (1)):

$$
\operatorname{Tcomf}=0.33 \operatorname{Trm}+18.8+3\left(\text { where } \operatorname{Trm}>10^{\circ} \mathrm{C}\right),
$$

where

Tcomf $=$ the maximum comfortable temperature $\left({ }^{\circ} \mathrm{C}\right)$; and

$\operatorname{Trm}=$ the running mean temperature for today weighted with higher influence of recent days $[39]\left({ }^{\circ} \mathrm{C}\right)$.

Trm can be calculated using Equation (2):

$$
\operatorname{Trm}=[1-\alpha] .\{\text { Ted }-1+\alpha . \text { Ted }-2+\alpha 2 . \text { Ted-3 } \ldots .\},
$$

where

Ted-1 $=$ the daily mean external temperature for the previous day $\left({ }^{\circ} \mathrm{C}\right)$;

Ted-2 $=$ the daily mean external temperature for the day before $\left({ }^{\circ} \mathrm{C}\right)$; and so on.

$\alpha$ is a constant; Tuohy et al. [40] suggest to use 0.8 for $\alpha$.

The CIBSE TM52 guideline assesses performance against three criteria. A zone is classified as overheating if it fails any two of the three criteria [41]. The criteria are defined in terms of $\Delta \mathrm{T}$, which is the difference between the actual operative temperature and the maximum acceptable temperature (Table 3). This is rounded to the nearest whole degree.

$$
\Delta \mathrm{T}=\mathrm{Top}-\mathrm{Tmax}
$$

Operative temperature (Top) articulates the joint effect of air temperature and mean radiant temperature along with the internal air movement as a single representative figure. For indoor airspeed less than $0.1 \mathrm{~m} / \mathrm{s}$, Top is calculated from the following equation [41]:

$$
\operatorname{Top}=(\mathrm{Ta}+\mathrm{Tr}) / 2
$$

where

$\mathrm{Ta}=$ air temperature $\left({ }^{\circ} \mathrm{C}\right)$; and 
$\operatorname{Tr}=$ mean radiant temperature $\left({ }^{\circ} \mathrm{C}\right)$.

A summary of the overheating assessment criteria is shown in Table 3.

Table 3. Overheating Assessment Criteria.

\begin{tabular}{ccc}
\hline & Assessment Criteria ${ }^{1}$ & Acceptable Deviations \\
\hline Criterion 1 & $\begin{array}{c}\text { Percentage of occupied hours during which } \Delta \mathrm{T}(\Delta \mathrm{T}=\mathrm{Top}-\mathrm{Tmax} \text { rounded to } \\
\text { the nearest whole degree) is greater than or equal to } 1^{\circ} \mathrm{C}\end{array}$ & Up to $3 \%$ of occupied hours \\
Criterion 2 & "Daily weighted exceedance" (We) in any one day $>6^{\circ} \mathrm{C} \cdot \mathrm{h}$ (degree $\cdot$ hours) & 0 day \\
Criterion 3 & Maximum temperature level (Tupp) $\Delta \mathrm{T}>4^{\circ} \mathrm{C}$ & $0 \mathrm{~h}$ \\
\hline
\end{tabular}

${ }^{1}$ Refer to Abbreviations for more information.

\subsection{Section $B$}

The aim of Section B is to assess the sensitivity of 5 passive design parameters which are representative of mitigating/worsening the thermal comfort conditions of the baseline condition. A sensitivity analysis is used to change the parameters in the baseline model to establish the effects that each one has on the system. The effects of various alternations on thermal comfort are carried out using the Simlab and Rsudio programmes. The complete set of baseline conditions and alternative conditions are shown in Table 4.

Table 4. Design options for assessment of sensitivity in condominiums.

\begin{tabular}{cccc}
\hline Construction & Baseline Condition & \multicolumn{2}{c}{ Alternative Conditions } \\
\hline Wall Material & Brick and Cement Rendering & Concrete Block and Rendering & $\begin{array}{c}\text { Lightweight Concrete } \\
\text { and Rendering }\end{array}$ \\
\hline Shading of Windows & Local Shading of Windows & No Local Shading of Windows & \\
\hline Balcony & Open Balcony & No Balcony & $75 \%$ \\
\hline Window Openable Area & $25 \%$ & $50 \%$ & \\
\hline Roof & tiles & tiles with $50 \mathrm{~mm}$ insulation & \\
\hline
\end{tabular}

Based on the results from Section A, a sensitivity analysis (SA) is carried out using two phases, namely screening experiments and optimisation [42]. Firstly, a set of 60 permutations of design parameters is developed using SimLab2.2 Sensitivity Analysis Software in a screening process to establishing the critical factors and not the interaction between the factors. A sequence of results is generated using the Morris Method. This method was selected for this study as it was designed for the screening of a large number of input factors with the outputs incorporating only "elementary effects" [43] of the inputs i.e., those factors with a profound effect on the output and those with a minimal effect. The number of permutations is calculated by the formula

$$
\mathrm{r} \times(\mathrm{k}+1)
$$

where $r$ is the number of levels and $\mathrm{k}$ the number of independent input factors [44].

The first step is to convert the factors and levels into a set of permutations for the energy modelling purposes. In the sample generations phase the parameters were identified as a set of discrete variables with a value of 0,1 or 2 depending on the alternative condition under consideration. The variable passive design strategy parameters (factors) to be assessed for this research are external wall material, the presence of shading devices over the windows, the presence of a balcony, the openable area of the apartment windows and the incorporation of insulation into the roof. The levels for each of these variable design parameters are shown in Table 5.

These variables are then passed through the pre-processor phase where SimLab converts the independent factors and levels into various permutations. The number of permutations that are carried out is dependent on the number of executions selected by the user. For the purpose of this 
study, the maximum number of executions of 60 was selected to obtain a higher level of accuracy. The permutations are then converted into an experimental matrix under the model execution phase. The complete process undertaken for analysing the incorporation of this data into the energy model represented graphically in Figure 6.

Table 5. Experimental factors and levels.

\begin{tabular}{cccc}
\hline Criterion & Level Value at $\mathbf{0}$ & Level Value at 1 & Level Value at 2 \\
\hline External Wall material (WM) & Baked brick & Lightweight concrete & - \\
Shading of Windows (SW) & shading & No shading & - \\
Balcony (BA) & Balcony & No Balcony & - \\
Window Openable Area (WA) & $25 \%$ & $50 \%$ & $75 \%$ \\
Roof Material (RM) & No insulation & insulation & - \\
\hline
\end{tabular}

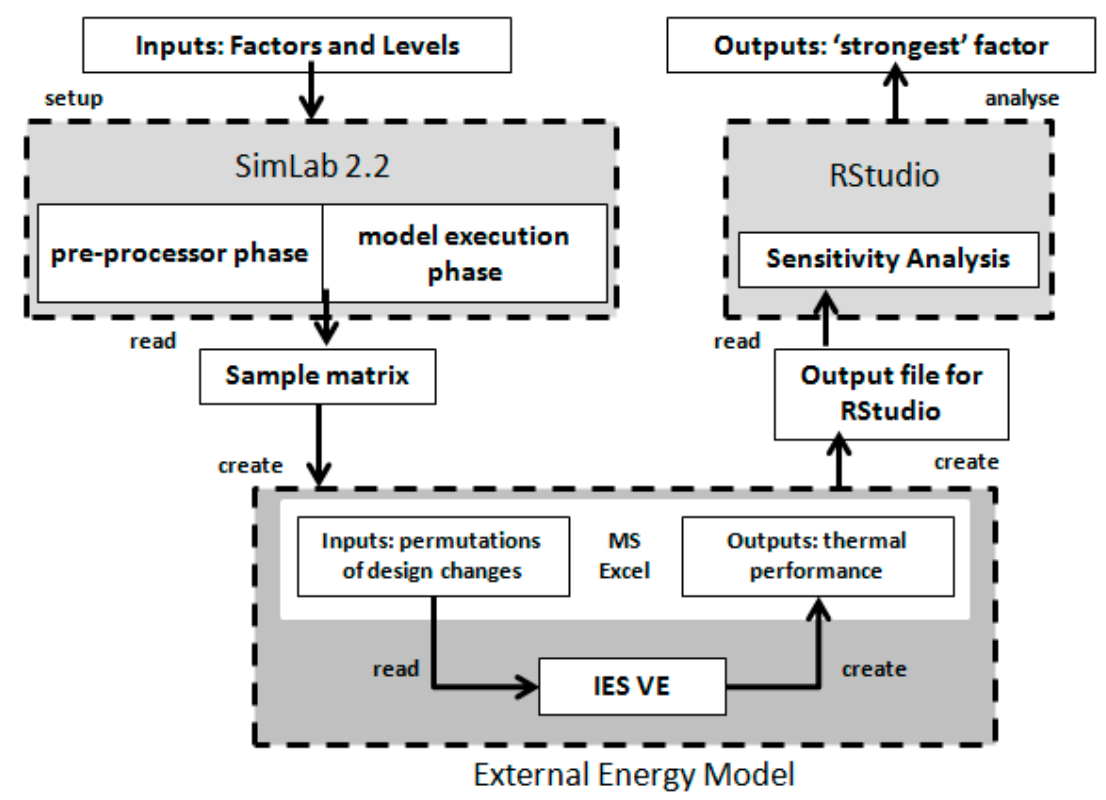

Figure 6. Graphical representation of SA strategy.

The baseline energy model is run for different scenarios, incorporating each of the sixty permutations. Once the simulations were completed in IES Virtual Environment, the optimization phase is carried out. Optimisation refers to the assessment of factor interaction and a system's variance from a statistics perspective. RStudio is used to carry out the optimisation analysis. $\mathrm{R}$ is an open source programming language for the statistical analysis. The programme enlists the use of "command-line scripting" for the creation of functions for statistical modelling. The results pertaining to the thermal performance of the model are fed into RStudio. The outputs from RStudio incorporate the sensitivities for each of the independent factors as well as the sensitivities of the factors interacted as pairs. The sensitivities are calculated based on the variances in the values of the three CIBSE TM52 criteria between the baseline model from Section A and each simulated permutation for the living room, bedroom and kitchen. A linear statistical analysis function is run for these living zones for each of the criterion. The $\mathrm{R}$ model defines discrete variables in the form of factors by accessing the value of the variable in a column of data to obtain the interaction between factors and can be calculated using Equation (6) below:

$$
\text { LR60.model }=\operatorname{lm}(\mathrm{c} 2 \sim \mathrm{WM}+\mathrm{SW}+\mathrm{BA}+\mathrm{WA}+\mathrm{RM}),
$$

where $\mathrm{c} 2$ refers to the column of data adhering to the CIBSE TM52 data, i.e., c2 is Daily Weighted Exceedance. WM is Wall Material, SW is Shading of Windows, BA is the presence of a Balcony, WA is 
the Window Openable Area and RM is Roof Material. The final output is a graphical representation of the permutations.

\section{Results and Discussion}

The simulations section evaluates the thermal comfort conditions based on the standard material composition of Baan Ua-Arthorn housing.

\subsection{Performance of Baseline Model of Case Study Housing Unit}

The results of the thermal performance of the baseline model were validated according to adaptive thermal comfort standards.

\subsubsection{Hours of Exceedance (He)}

In Figure 7, the percentage of hours of exceedance is shown for the living zones on the ground floor and the fourth floor. The initial observation is that the apartments greatly exceed the limiting factor of 3\%. The apartments on the fourth floor are shown to have worse thermal performance than those on the ground floor. The worst performing apartment is the edge unit on the top floor (two exposed external walls). The living room in this unit is the worst performing zone with a performance that exceeds the limiting factor by over five times at a value of $16.14 \%$. The bedroom exceeds the limiting factor by over three times with a value of $10.06 \%$.

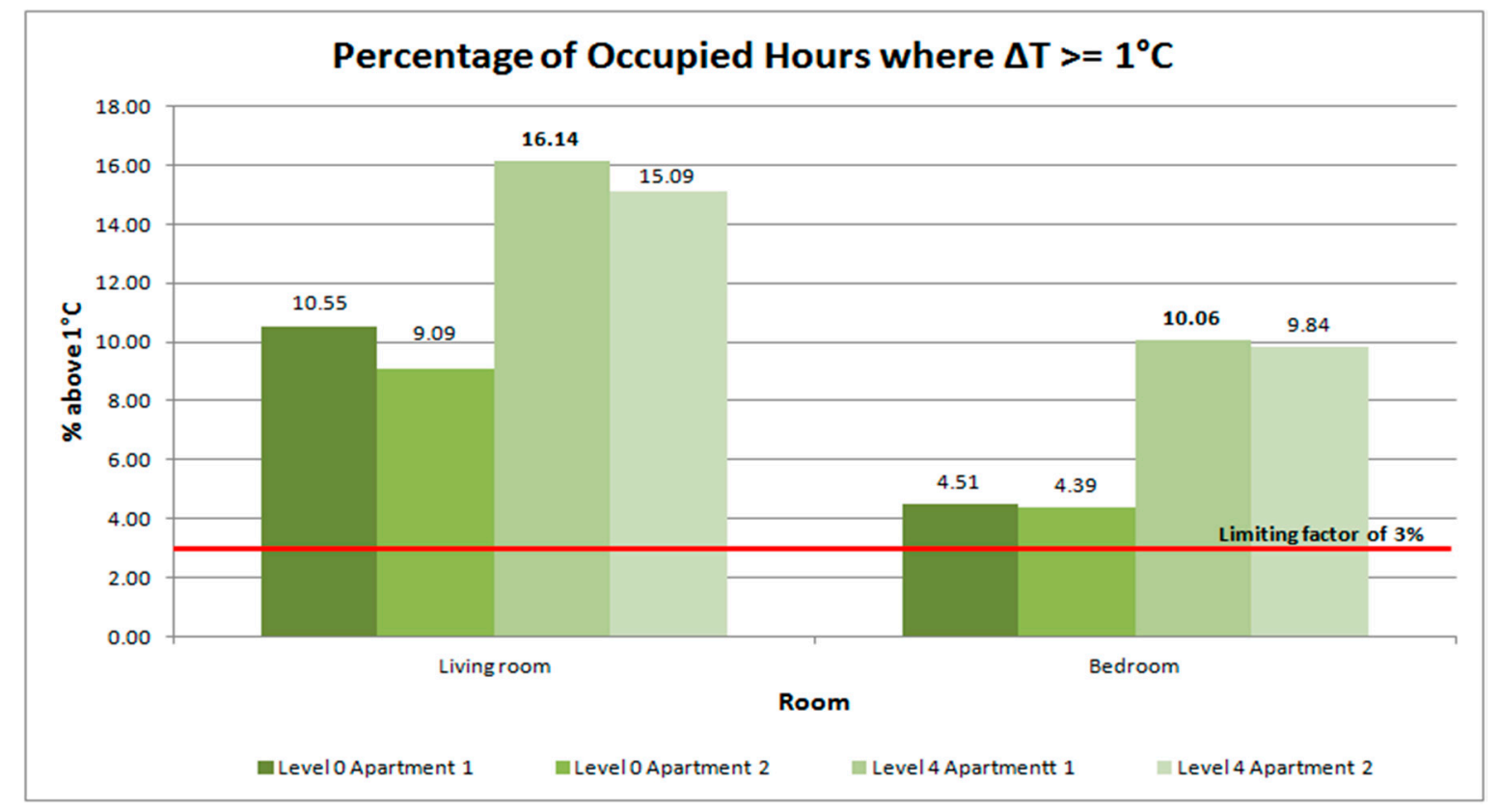

Figure 7. Performance of apartment according to criterion 1.

\subsubsection{Daily Weighted Exceedance (We)}

This criterion was assessed by counting the number of days in a calendar year where the We exceeds $6{ }^{\circ} \mathrm{CHr}$ while that zone was occupied. In compliance with criterion 2, a zone should exceed this value for no days. The results for the baseline case are shown in Figure 8.

As with criterion 1, the apartments are shown to exceed the limits of failure with the corresponding top floor apartment showing the greatest signs of overheating. Within this apartment the living room surpasses $6{ }^{\circ} \mathrm{CHr}$ for 115 days and the bedroom surpasses $6{ }^{\circ} \mathrm{CHr}$ for 77 days out of 365 days, respectively. This indicates that the zones within the apartment spend a large percentage of time at very high temperatures throughout the year. 


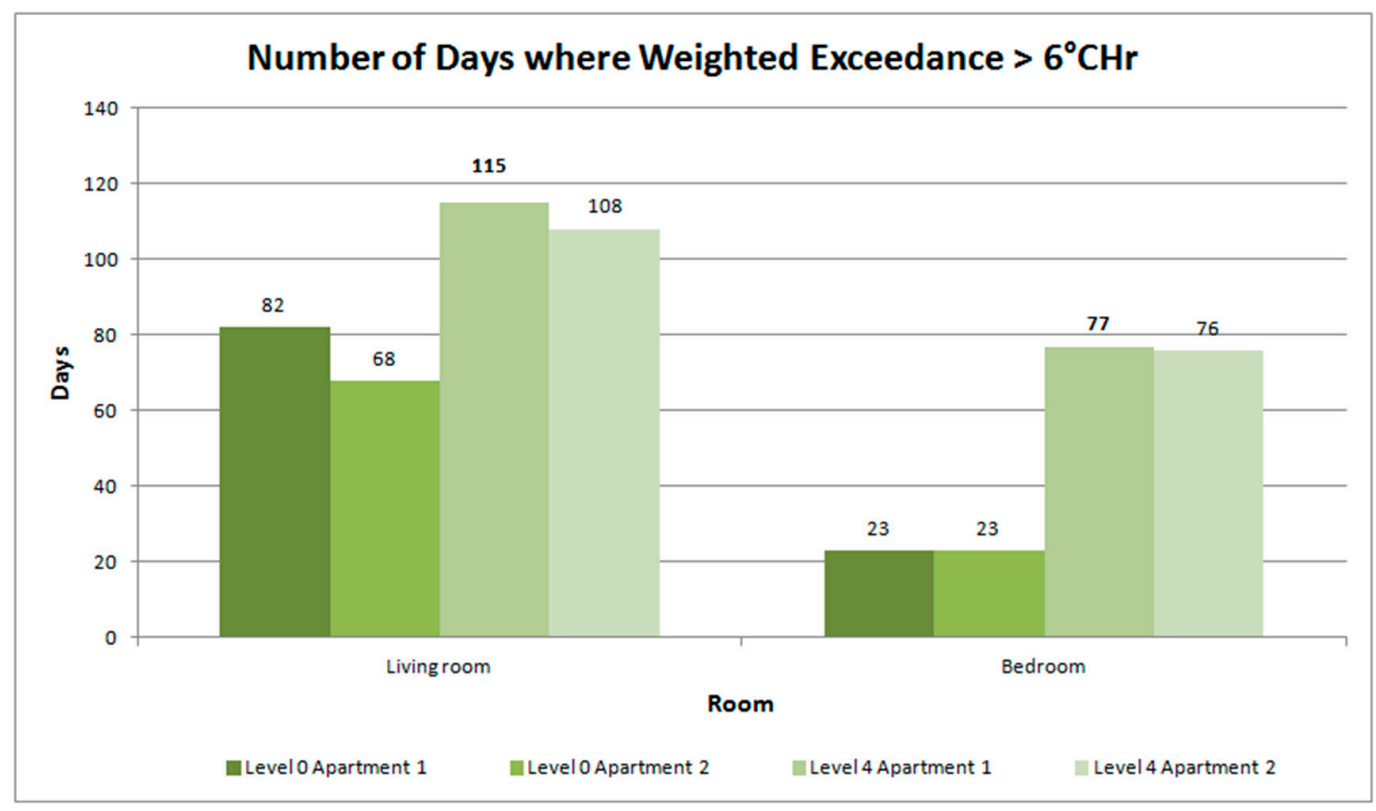

Figure 8. Performance of apartment according to criterion 2.

\subsubsection{Daily Weighted Exceedance (We)}

The apartments on the lower ground are again found to perform better than those on the top floor. The living room is observed to be the critical zone within the apartments as it fails criterion 3 for three of the four apartments (Figure 9). The differentiation in the performance of the apartments on the lower floor is attributed to the location of the apartments. The unit with two exposed walls (apartment 1) has reduced capacity for providing thermal comfort within the adaptive comfort limits. The living room in apartment 1 on the ground floor and top floor exceed $4{ }^{\circ} \mathrm{C}$ by $4 \mathrm{~h}$ and $11 \mathrm{~h}$ annually, respectively.

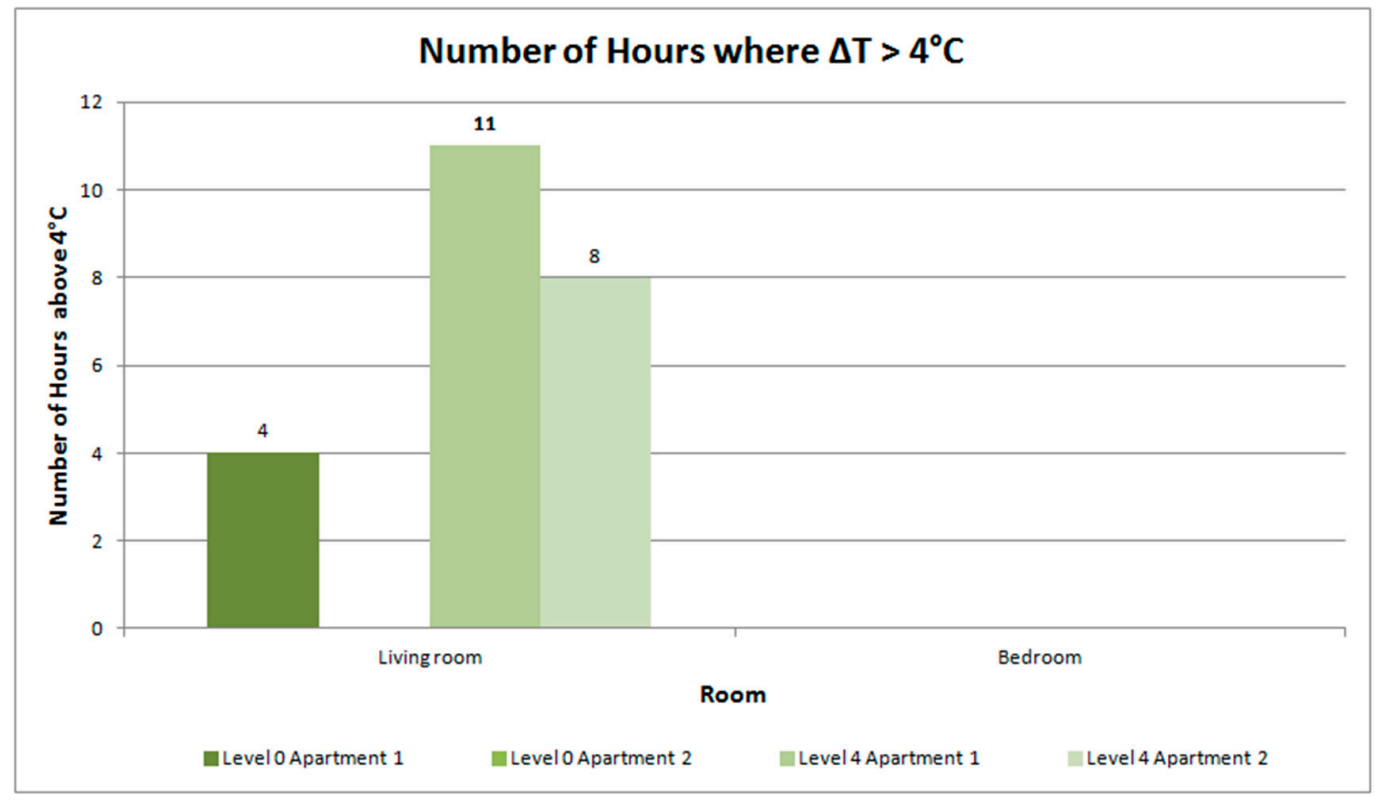

Figure 9. Performance of apartment according to criterion 3.

The zones under consideration within the case study housing unit are found to exceed the acceptable limits of two or more of the CIBSE TM52 criteria. The critical zone of concern is the living room as it incorporates the internal heat gains from the kitchen as these are interleading rooms. 
The apartment with the poorer thermal performance was shown to be apartment 1 on the top and ground floors. This is attributed to the material properties of the structural features of the building envelope. This apartment is constructed with two exposed external walls allowing for a higher rate of heat transfer.

In conjunction with the location of the apartments on a level, the height of the condominium influences the thermal performance of the apartments. The building is subjected to effects from "buoyancy-driven air movement" [6]. Hot air from the lower levels rises up through the building and with no means of escaping the living zones, accumulates on the top levels. Combining this with the effects from the building envelope corresponds to the inadequate thermal performance of apartment 1 on level four for all three criteria.

In terms of criterion 3, the bedrooms in each of the apartments do not show exceedance of $4{ }^{\circ} \mathrm{C}$ over the year. This can be attributed to the classification of the bedroom as a "night-zone" [30] which means it is only occupied at night. These criteria are assessed based on when the zone is occupied. This means that the external night time temperature drop below a certain point whereby the addition of internal gains from people is not significant enough to raise the temperature above Tupp. In comparison, the living room is either partially or fully occupied at all times. This incorporates those periods where external daytime temperatures reach their maximum.

While these results show that this housing model far exceeds what is deemed acceptable for TM52, it is important to note that TM52 is designed as a tool for mainly assessing overheating in summer in Europe and the UK. Thus, its application to tropical climates tends to underestimate the amount of time spent at high temperatures (which in these regions is most of the day). This is particularly significant for the application of criterion 2 . While this level of severity of overheating may be more unacceptable in temperate zones, inhabitants in Thailand are less critical of these conditions. These observations also correlate with those made by Eyre [23] for low income housing in Tanzania and should be incorporated into continued research into establishing adequate thermal comfort criterion for tropical regions [18].

\subsection{Summary of Findings}

\subsubsection{Diurnal Temperature Fluctuation}

The 24-h temperature profiles of the living room, the bedroom and the kitchen for the hottest day of the year (29 April) are shown in Figures 10-12, respectively. The variation of room temperature with time shows a low diurnal temperature swing with the internal temperature patterns correlate to the external temperature changes. The internal operating temperatures remain relatively high throughout the day and night, fluctuating between the maximum acceptable temperature and the upper limit for overheating. The external night temperatures do not drop significantly enough to induce rapid cooling of the indoor environment.

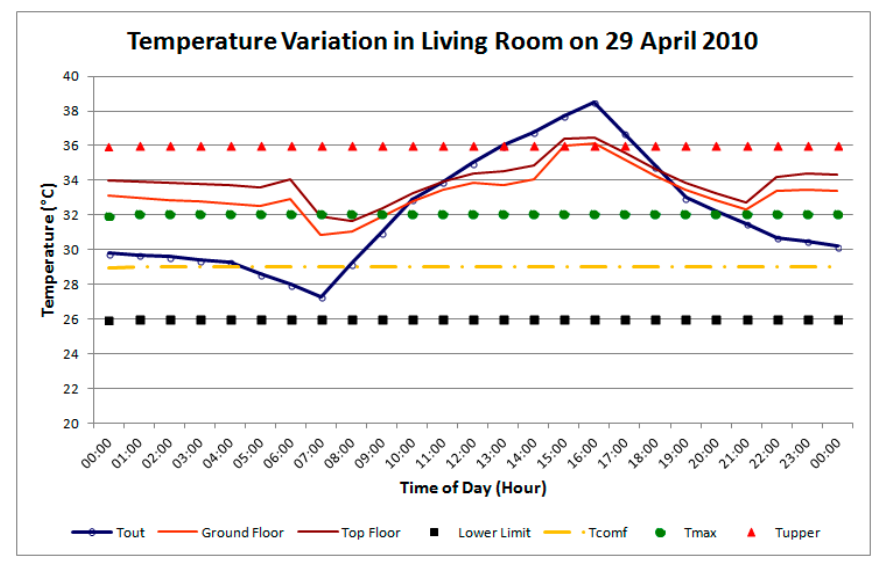

Figure 10. Diurnal temperature variation of living room. 


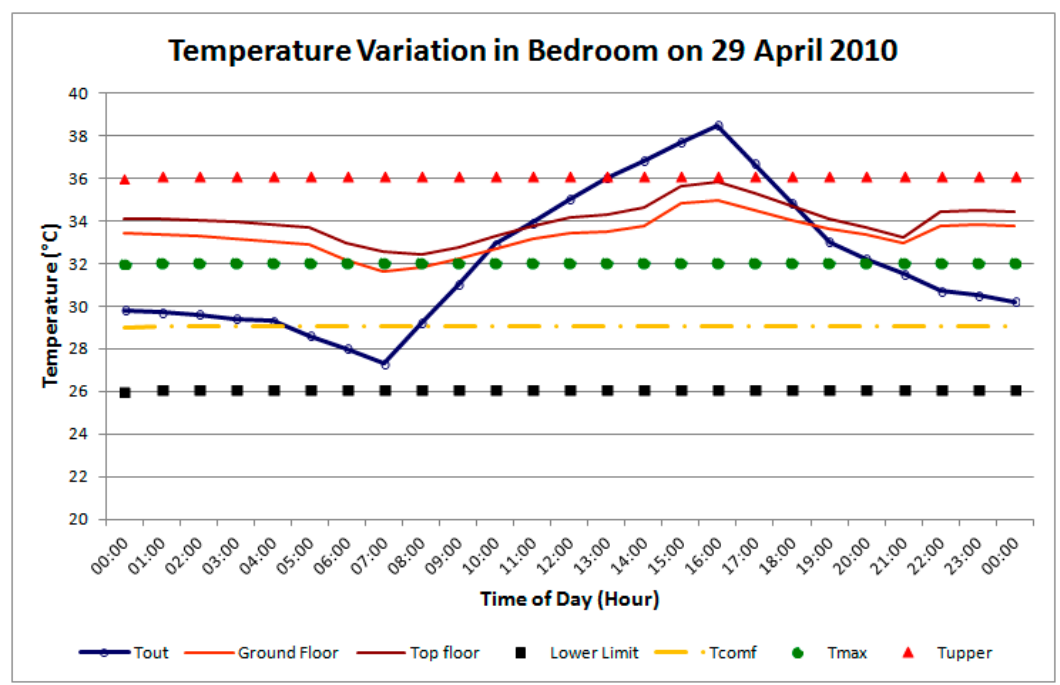

Figure 11. Diurnal temperature variation of bedroom.

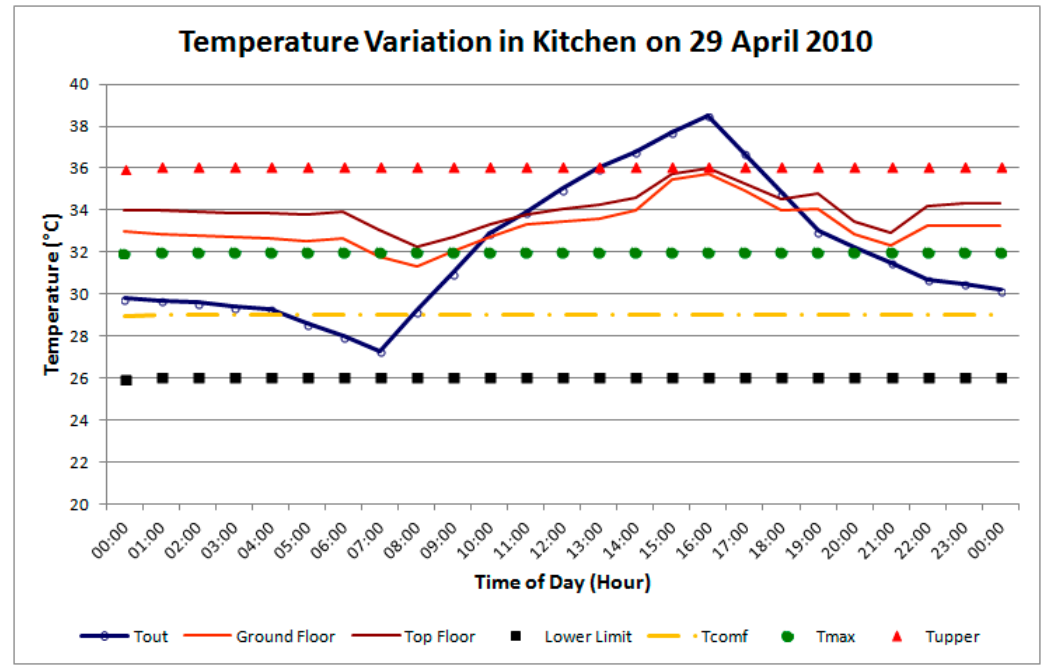

Figure 12. Diurnal temperature variation of kitchen.

\subsubsection{Influence of Building Envelope on Thermal Performance}

The thermal mass has a significant influence on the cyclical nature of the temperature changes within the apartment units. As the external air temperature rises, the external walls and floor slab will absorb and store the heat. Once the external temperatures start to drop (16:00) the heat within these materials rises to the surface and is released into the internal environment. This elevates the internal night temperatures of the living zones and the indoor temperature starts to drop off at the same time, however at a much slower rate due to thermal storage in the indoor materials. This process is represented in Figure 13, where the fluctuations in the conduction gains of the external walls are influenced by changes in the outdoor temperature. In this case the external walls refers to the impact of all indoor thermal mass (floor, ceiling, internal walls and external walls) releasing stored heat, thus keeping indoor temperatures high. The lack of lag time between peak outdoor and peak indoor temperatures is attributed to the high ventilation rate during the day when the windows are open. This has the resultant effect of moderating the operating temperatures of the living zones. The critical issue is that this effect keeps the operating temperatures at high levels throughout the day, inhibiting sufficient cooling to occur. 


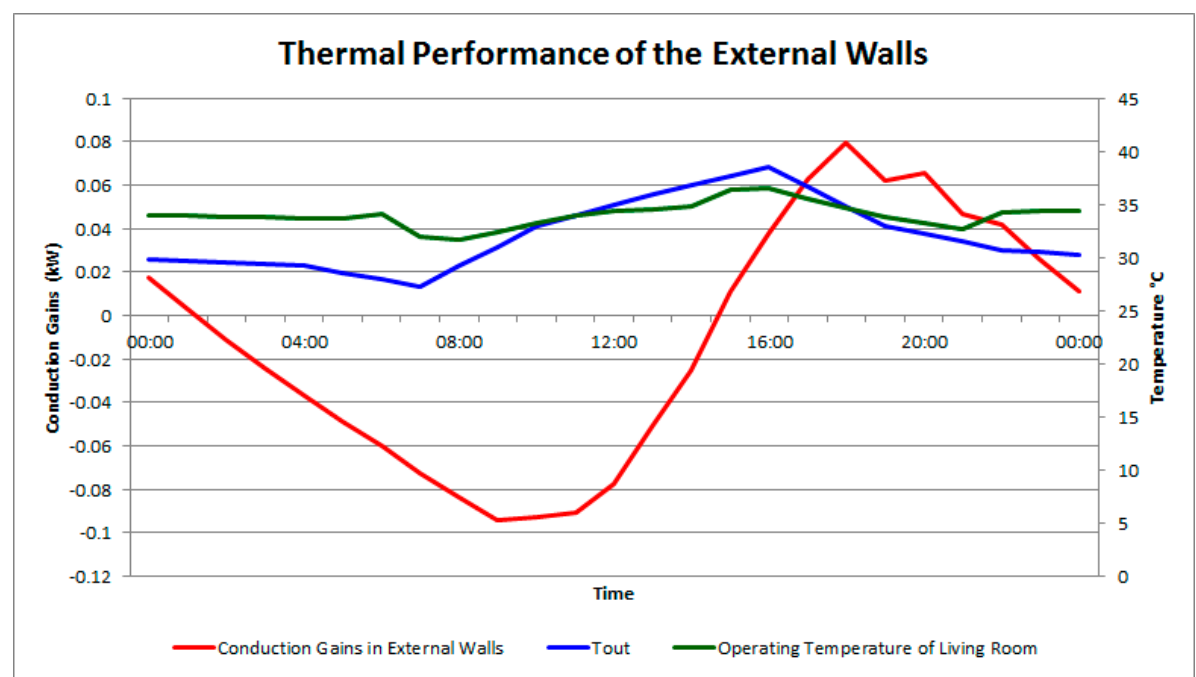

Figure 13. Thermal storage effect of external walls.

In this study, the windows were assumed to be closed at night due to security and social reasons. This limits the amount of airflow in the apartment at night, particularly in the bedroom which has only one window. With insufficient mechanisms to abate excess heat that is released into the zone at night, the operating temperatures of the apartment remains elevated. Figure 14 shows that about a $2{ }^{\circ} \mathrm{C}$ reduction in the operating temperature is induced in the bedroom if the window remains open at night and airflow is improved.

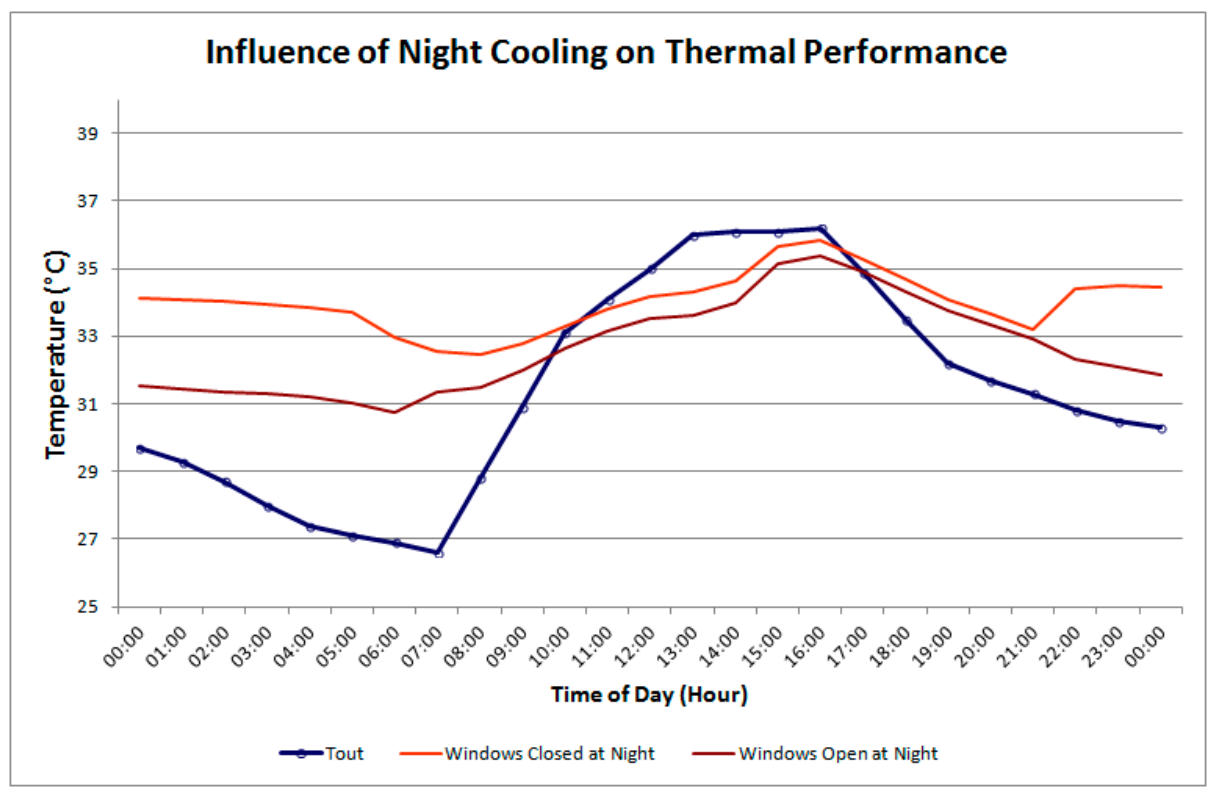

Figure 14. Improvement of ventilation with night cooling.

\subsubsection{Influence of Natural Ventilation on Thermal Performance}

The high internal operating temperatures are a result of both convection and radiation heat which build up over the day. Without any form of mechanical cooling, natural air exchanges are responsible for the removal of this heat; however, the current construction of the building and each apartment has a significant influence on the ventilation. While the narrow layout may aid in the circulation of air, the number and type of openings, the layout of the rooms and the restrictions of adjacent apartments 
means that ventilation between rooms is highly restricted. Figure 15 shows the quantity of airflow that enters into each zone. The value Wc refers to the minimum wind speed that is needed to ensure indoor comfort is maintained [10]. The daytime flow rate ranges from $0.11 \mathrm{~m} / \mathrm{s}$ to $0.38 \mathrm{~m} / \mathrm{s}$. The windows remain closed at night which accounts for this rate dropping to zero overnight. The maximum airflow rate in the living room and kitchen is $0.81 \mathrm{~m} / \mathrm{s}$ and $2 \mathrm{~m} / \mathrm{s}$ respectively. The high airflow rate in the kitchen is attributed to the presence of the louvre window and the doorway leading into the living room. The window overlooks the hallway and allows for more penetration of airflow through the openings. To achieve a comfortable indoor environment, natural ventilation should provide an indoor air velocity of $0.4 \mathrm{~m} / \mathrm{s}$.

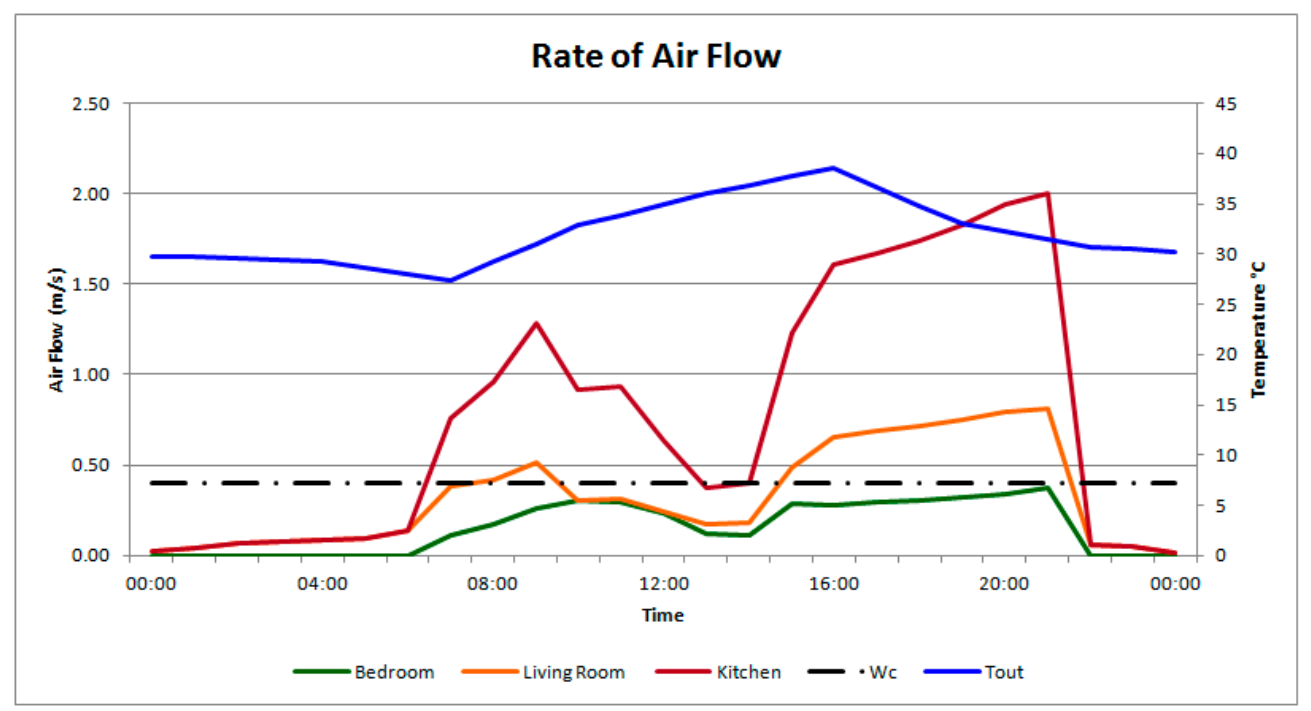

Figure 15. Rate of airflow through the apartment on 29 April 2010.

Essentially, the amount of cross ventilation that can occur through a single unit is highly restricted by design elements and local climatic conditions. The heat builds up and with no method of removal stagnates to increase the operating temperature as well as the discomfort of the internal environment.

\subsubsection{Influence of Roof on Thermal Performance}

The analysis of the progression of the operating temperature change over the $24 \mathrm{~h}$ showed that the roof is subject to a significant temperature change over the course of the day. The temperature change in the roof is seen to begin at 9:00 as the external temperature rises and the solar radiation increases (Figure 16). The temperature of the apartments is seen to be about $5{ }^{\circ} \mathrm{C}$ higher than in those on the ground floor at this time. By 14:00, the roof reaches its highest temperature.

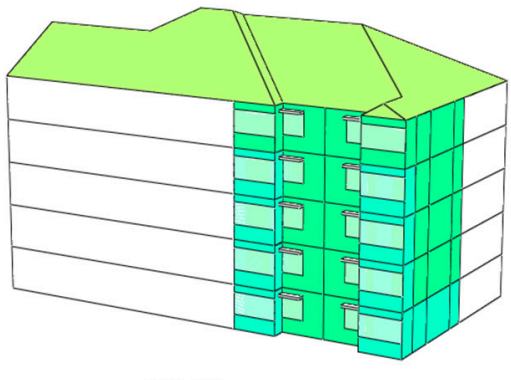

09:00

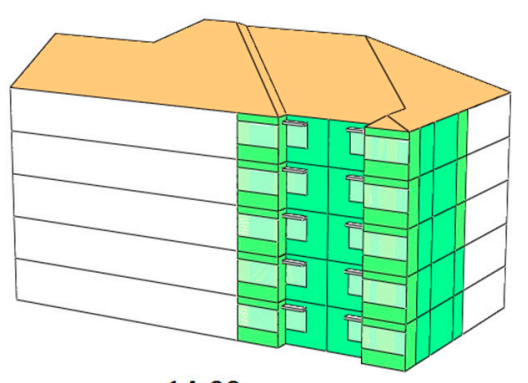

$14: 00$

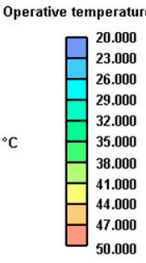

Figure 16. Progression of temperature change in the roof. 
The corresponding conduction gains in the roof over $24 \mathrm{~h}$ are shown in Figure 17. The conduction values range from a minimum of $1.98 \mathrm{~kW}$ at 7:00 to a maximum value of $21.86 \mathrm{~kW}$ at 12:00. This corresponds to the increase in direct solar exposure over the day. The negative gains during the night are associated with reversal in the direction of heat transmission, i.e., the roof temperature is higher than the external temperature.

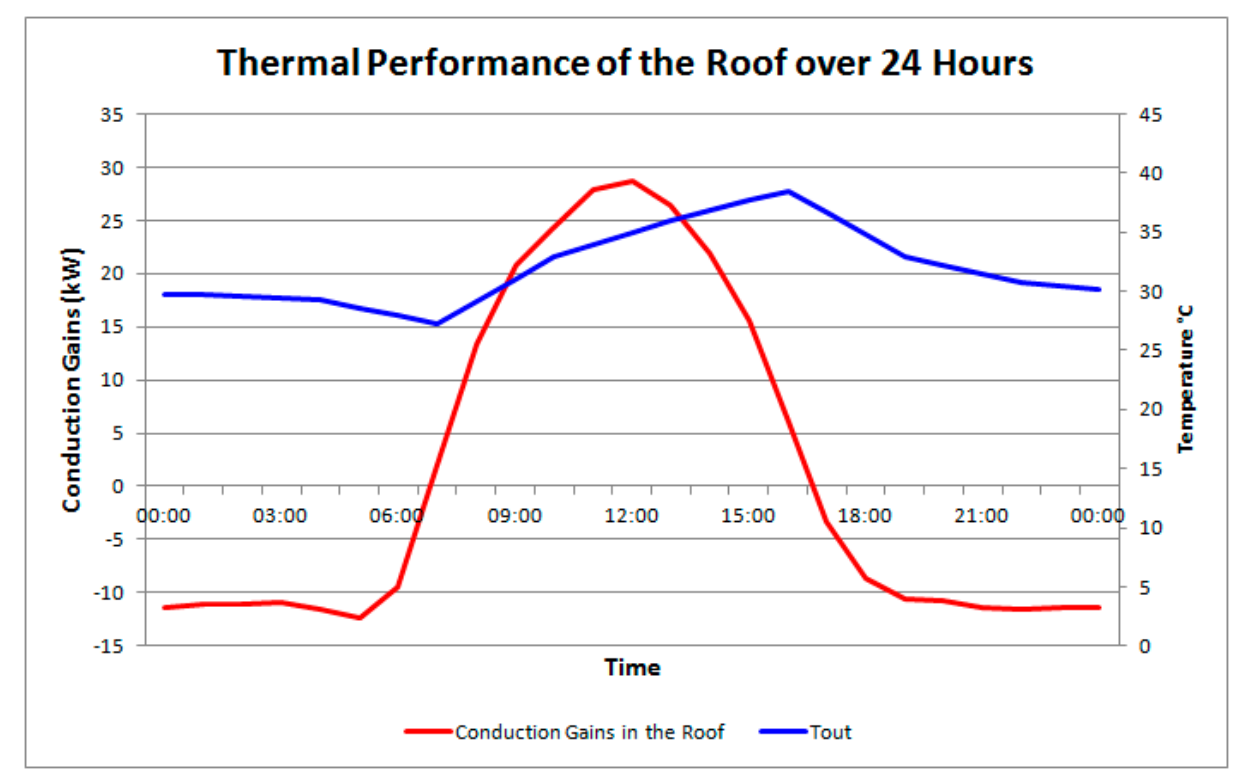

Figure 17. Severity of conduction gains in the roof on 29 April 2010.

Various DTS studies that have been carried out on houses in tropical regions have shown that the roof is a key area of concern in terms of thermal performance $[23,24,30,45,46]$. The roof is continually exposed to high levels of solar radiation and materials used in roof construction tend to have low thermal storage and low thermal resistance properties. This means that a building remains vulnerable to high levels of heat transmission occurring through the roof. In the case study building, there is a significant difference in operating temperatures between the apartments on the upper level and those on the ground floor. This is partly due to the stack effect of air; however, this can also be attributed to the high magnitude and the rapid transmittance of heat energy through the roof.

\subsection{Section B: Summary of Results}

The distribution of the data set for each of the parameters is presented in box plot format. The important values include the median or central tendency measurement, the maximum and minimum number of days on overheating. The most important observations that can be made from these results include the distribution of the number of days of overheating that is experienced based on the parameter and its respective level. A change in a parameter that shows a smaller variability in the data set indicates a closer correlation between the individual values in that set (the mean is more representative of the data set). Although the range and the interquartile range are important to show the spread of the data, these points are determined from only two points in the entire data set. Thus from a statistics point of view, the values of the mean and the median are more adequate indications of the sensitivity of the parameter in the performance of the system.

\subsubsection{Roof and Wall Material}

The incorporation of $50 \mathrm{~mm}$ of insulation in the roof is observed to have the greatest change in thermal performance within the apartment (Figure 18). The mean number of days of overheating is reduced to 98.56 when the wall material is changed to level 1, compared to 124 days at level 0 . 
Insulation reduces the amount of heat gain that can enter into the space between the roof and the ceiling. This means that there is a restriction on the flow of heat in the day and at night. The maximum and minimum number of days of overheating was reduced from 185 to 125 and 115 to 30 days, respectively. The spread of data points is greatly improved by incorporating insulation. This means that less variance is seen in the effects of overheating.

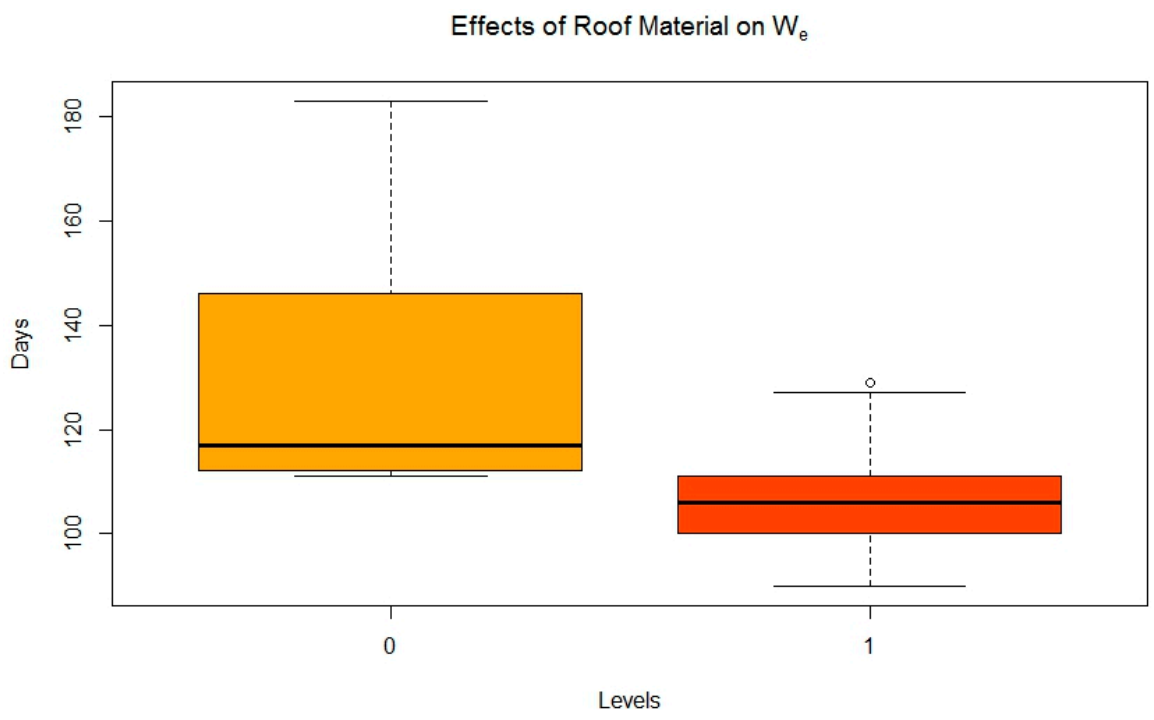

Figure 18. Individual sensitivity: roof material.

The change of the wall material from brick (level 0) to lightweight concrete (level 1) is seen to be less critical than changes in the other parameters. Figure 19 shows the reason for this is that the results of the two data sets overlap significantly. A change in wall material resulted in a reduction of overheating to a mean of 123.97 days, with the median value changing from 170 to 160 days. Although the maximum and minimum number of days of overheating was reduced from 175 to 142 and from 115 to 30 days, respectively, the value of the median is a better indication of the typical number of days of overheating. The outlying value represents a significant irregularity in the distribution which falls outside 1.5 times the upper quartile rage.

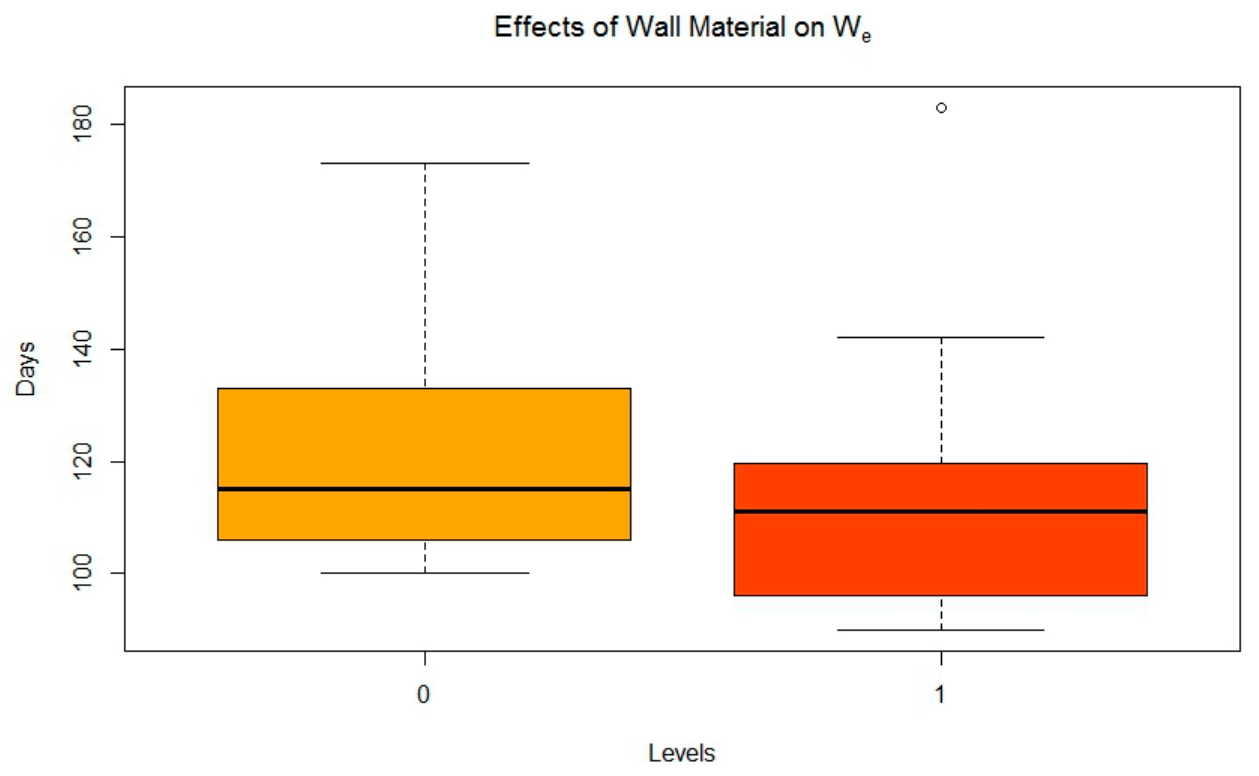

Figure 19. Individual sensitivity: wall material. 
The total sensitivity effects of the combinations of uncertainty in the distributions of both wall material and roof material are shown in Figure 20. The levels on the x-axis show the effects of changing first the wall material $(1,0)$, the roof material $(0,1)$ and then both wall material and roof material $(1,1)$. The combined incorporation of $50 \mathrm{~mm}$ insulation and the change of wall material to lightweight concrete reduced the mean number of days of overheating to 101.59 with the maximum reaching 130 days compared to 172 days of the baseline condition. The effects in the combination of the sensitivities can be seen on the graph where the median value has decreased from 135 days at the baseline level to 100 days with both parameters set to level 1 . The elementary effects of the incorporation of roof material only, however, were shown to reduce the mean number of days of overheating to 98.56. This indicates that although changing the value of these parameters both to level 1 would elicit a decrease in the severity of overheating experienced in the apartment, changing the roof material only has a greater effect in reducing the severity of overheating. As a caveat in multistory buildings, roof insulation primarily impacts thermal conditions on the top floors. In terms of this, if the sensitivity analysis related the impact of action to number of apartments impacted, the outputs yield different results.

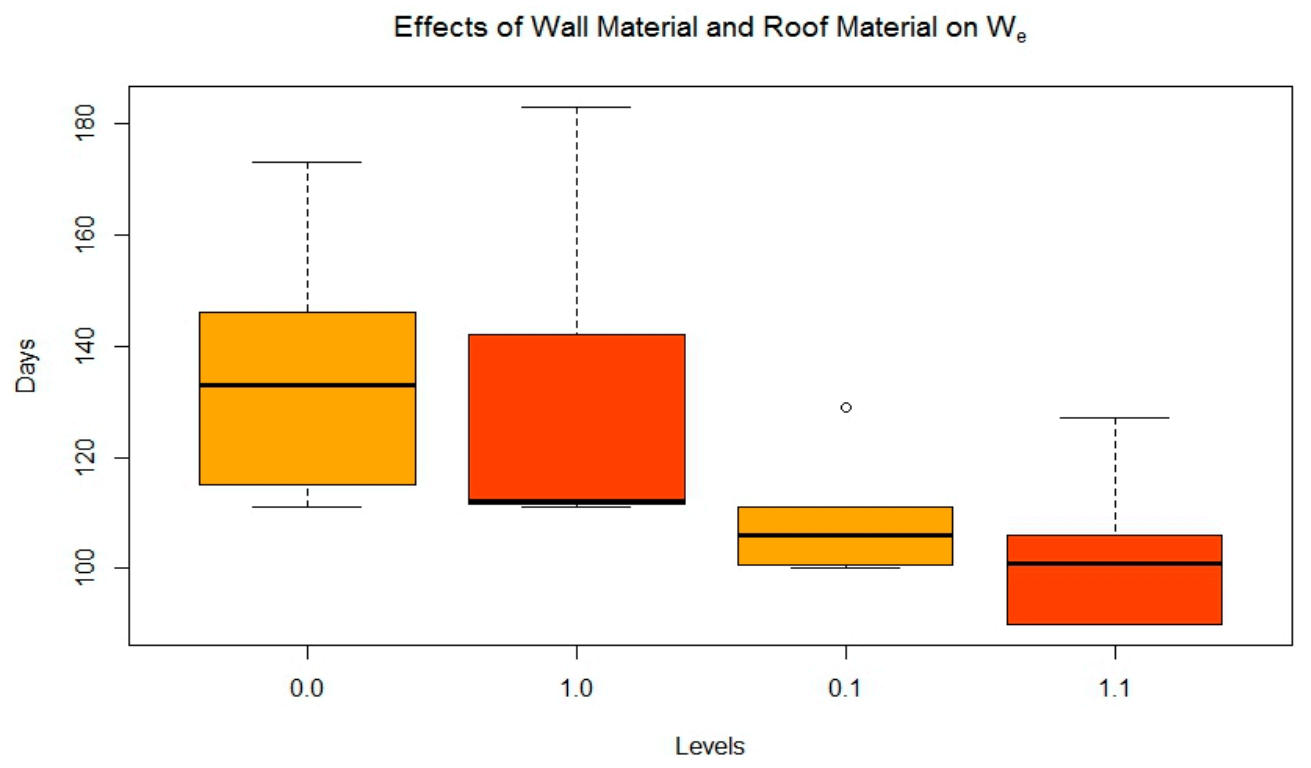

Figure 20. Total sensitivities: wall material and roof material.

\subsubsection{Balcony and Window Openable Area}

The impact of ventilation on the thermal performance of the building was discussed under summary of findings. The sensitivity of this parameter is essentially assessing for how a decrease in ventilation through the apartment would influence the thermal performance of the design. This parameter was seen to have the second largest effect on the system after the roof material. The graphical representation of these results is shown in Figure 21. At level 1 (the balcony is closed), the maximum number of days of overheating has increased from 118 to 183 . The mean was seen to increase to 150.45 days. The already stilted airflow through the living room is further exacerbated once the balcony is removed. This indicates that the temperature of the living zones stays at elevated temperatures for longer periods without any form of ventilation. This is expected in a region with high humidity as well as low minimal air movement. The presence of the balcony has a profound influence on the natural ventilation through the apartment. 


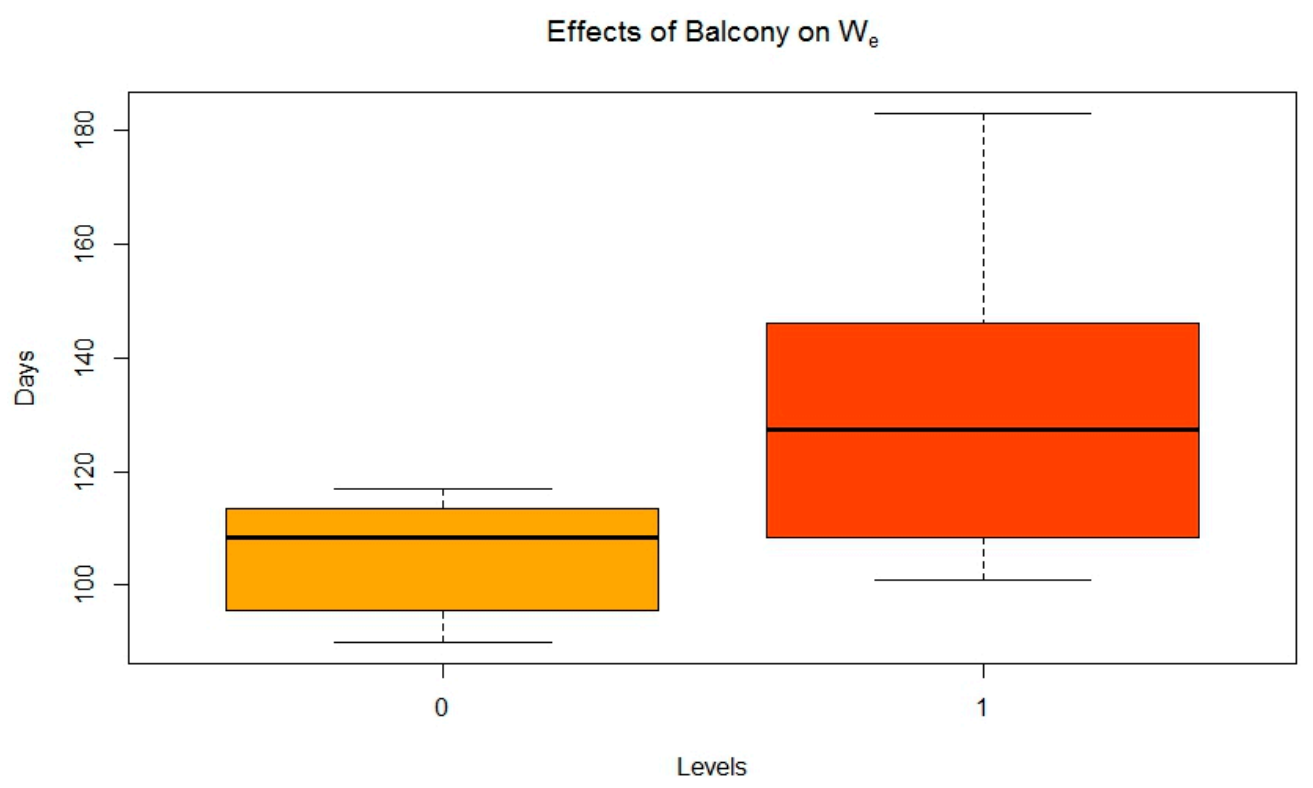

Figure 21. Individual sensitivity: Balcony.

In terms of the openable area of the windows, this is also a measure of the amount of ventilation that is generated in the apartment. This parameter was set at three different levels to assess the extreme variability of the importance of opening size on ventilation and thus the thermal performance of the apartment (Figure 22). The baseline condition for window openable area is $25 \%$ (level 0). The mean number of days of overheating at levels 1 and 2 (50\% and 75\% openable area) were determined to be 116.34 and 110.63 days, respectively. When the openable area is set to $50 \%$, the variability of the data set was increased. The nature of the plot can be attributed to single data points that lie further away from the mean, which is why the median (112 days) is a better representation of this data set. At level 2, the variability of the dataset is reduced and the mean is a more adequate representation of how this parameter influences the performance. Essentially the system is shown to be highly sensitive to a change in this parameter.

Effects of Window Openable Area on $\mathrm{W}_{\mathrm{e}}$

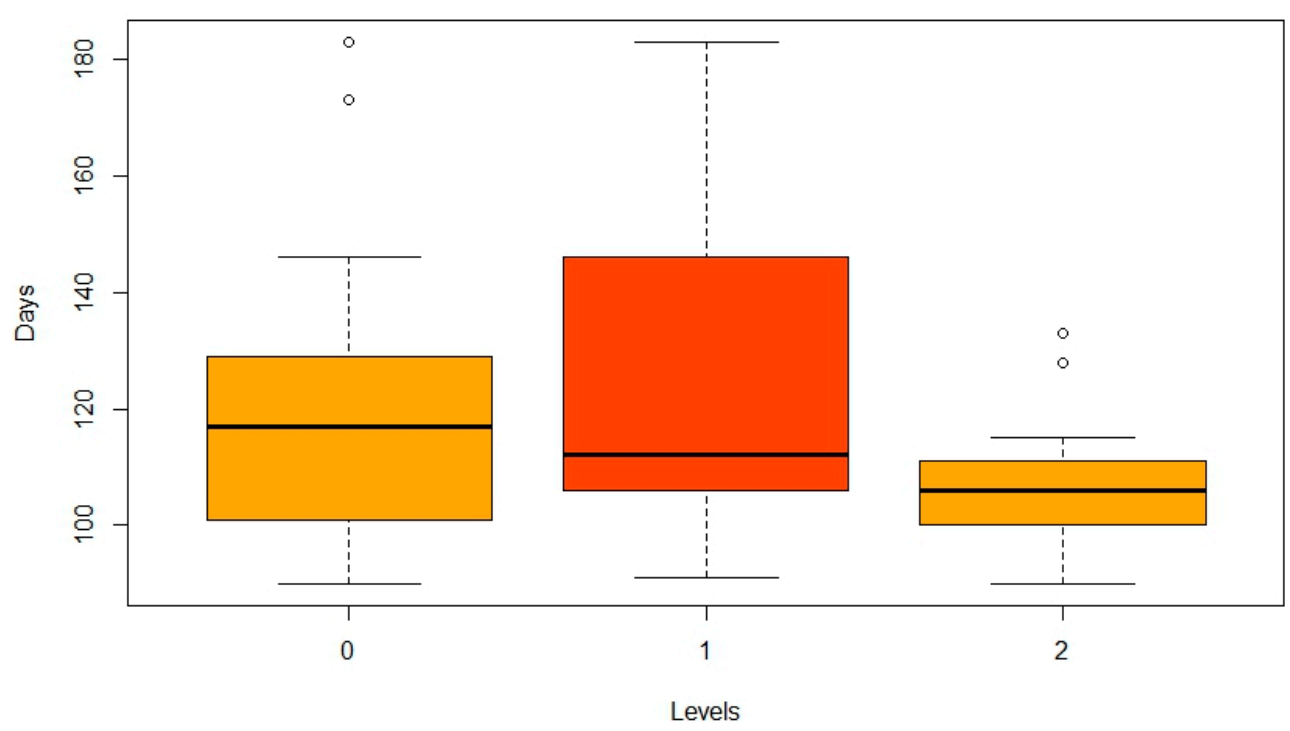

Figure 22. Individual sensitivity of window openable area. 


\section{Conclusions}

In terms of the baseline model, apartment 1 on level four has the worst thermal performance because of its proximity to the roof, the effect of hot air movement into this space and the structural characteristics of the apartment envelope. There is a lack of diurnal temperature variation within the apartments. The internal operating temperatures remain relatively high throughout the day and night, ranging from a maximum of $38.5^{\circ} \mathrm{C}$ to a minimum of $27.3^{\circ} \mathrm{C}$. This is not significant enough to influence night cooling. The roof is a key area of concern due to its high U-value, the surface area and the level of exposure to solar gains. This induces a high transmittal of heat into and out of the building. This has a significant effect on the operating temperatures of the apartments on the top floor.

The sensitivity analysis showed that the main effects (effect of a change in one parameter while the others are held steady) of the parameter changes have a greater influence on the performance of the system and are an adequate representation of parameter sensitivity. The system is shown to be most sensitive to a change in the roof material and the incorporation of a balcony into the design. The parameters that are least sensitive to changes in the system include the shading of windows and wall material. The mean number of days of overheating was reduced to 98.56 with the incorporation of $50 \mathrm{~mm}$ insulation and increased to 150.45 when the balcony was removed. These effects can be attributed to a reduction of heat gain through the roof when insulation is incorporated but an increase in heat gain due to a lack of ventilation without a balcony opening.

Acknowledgments: This document is an output from a research project "Energy and Low-Income Tropical Housing" co-funded by UK aid from the UK Department for International Development (DFID), the Engineering and Physical Science Research Council (EPSRC) and the Department for Energy and Climate Change (DECC), for the benefit of developing countries. The views expressed are not necessarily those of DFID, EPSRC or DECC.

Author Contributions: Authors equally contributed to the paper.

Conflicts of Interest: The authors declare no conflict of interest.

\section{References}

1. Golubchikov, O.; Badyina, A. Sustainable Housing for Sustainable Cities: A Policy Framework for Developing Countries; UN-HABITAT: Nairobi, Kenya, 2012; p. 73.

2. Hannula, E.-L. Going Green: A Handbook of Sustainable Housing Practices in Developing Countries; UN-HABITAT: Nairobi, Kenya, 2012; p. 124.

3. French, M.A.; Majale, M.; Tipple, G. Affordable Land and Housing in Asia. Available online: https:// unhabitat.org/books/affordable-land-and-housing-in-asia-2/ (accessed on 29 July 2015).

4. Kritayanavaj, B. Affordable Housing in Thailand. Available online: https://sites.google.com/site/ prcudweb / e-library (accessed on 15 June 2015).

5. Chiarakorn, S.; Rakkwamsuk, P.; Aransiri, K.; Aneksaen, N.; Parnthong, R. Evaluation of greenhouse gas emission from residential buildings in Thailand. In Proceedings of the Asian Conference on Sustainability, Energy \& the Environment Official Conference, Osaka, Japan, 12-15 June 2014.

6. Suenderman, T. Energy Efficiency in Affordable Low-to-Medium-Income Urban Housing of the National Housing Authority of Thailand; Deutsche Gesellschaft für Internationale Zusammenarbeit (GIZ): Bonn, Germany, 2005.

7. Hwang, R.-L.; Cheng, M.-J.; Lin, T.-P.; Ho, M.-C. Thermal perceptions, general adaptation methods and occupant's idea about the trade-off between thermal comfort and energy saving in hot-humid regions. Build. Environ. 2009, 44, 1128-1134. [CrossRef]

8. Archer, D. Social capital and participatory slum upgrading in Bangkok, Thailand. University of Cambridge, 2010. Available online: https:/ / www.repository.cam.ac.uk/handle/1810/244821 (accessed on 17 June 2015).

9. Ahmed, K.S. Comfort in urban spaces: Defining the boundaries of outdoor thermal comfort for the tropical urban environments. Energy Build. 2003, 35, 103-110. [CrossRef]

10. Tantasavasdi, C.; Srebric, J.; Chen, Q. Natural ventilation design for houses in Thailand. Energy Build. 2001, 33, 815-824. [CrossRef] 
11. Santamouris, M.; Pavlou, K.; Synnefa, A.; Niachou, K.; Kolokotsa, D. Recent progress on passive cooling techniques Advanced technological developments to improve survivability levels in low-income households. Energy Build. 2007, 39, 859-866. [CrossRef]

12. Höppe, P. Improving indoor thermal comfort by changing outdoor conditions. Energy Build. 1991, 16, 743-747. [CrossRef]

13. Vallati, A.; De Lieto Vollaro, A.; Golasi, I.; Barchiesi, E.; Caranese, C. On the impact of urban micro climate on the energy consumption of buildings. Energy Procedia 2015, 82, 506-511. [CrossRef]

14. Antarikananda, P.; Douvlou, E.; McCartney, K. Lessons from traditional architecture: Design for a climatic responsive contemporary house in Thailand. In Proceedings of the PLEA2006 23rd Conference on Passive and Low Energy Architecture, Geneva, Switzerland, 6-8 September 2006; pp. 11-43. Available online: http:/ / www.researchgate.net/profile/Kevin_Mccartney2/publication/242123373_Lessons_from_ traditional_architecture_Design_for_a_climatic_responsive_contemporary_house_in_Thailand/links / 53f3d9fc0cf256ab87b79921.pdf (accessed on 1 August 2015).

15. Arnfield, A.J. Koppen Climate Classification. Available online: http://www.britannica.com/EBchecked/ topic/322068/Koppen-climate-classification (accessed on 29 May 2015).

16. Prianto, E.; Depecker, P. Optimization of architectural design elements in tropical humid region with thermal comfort approach. Energy Build. 2003, 35, 273-280. [CrossRef]

17. Brager, G.S.; de Dear, R.J. Thermal adaptation in the built environment: A literature review. Energy Build. 1998, 27, 83-96. [CrossRef]

18. Nguyen, A.T.; Singh, M.K.; Reiter, S. An adaptive thermal comfort model for hot humid South-East Asia. Build. Environ. 2012, 56, 291-300. [CrossRef]

19. Nicol, J.F.; Humphreys, M.A. Adaptive thermal comfort and sustainable thermal standards for buildings. Energy Build. 2002, 34, 563-572. [CrossRef]

20. Feriadi, H.; Wong, N.H. Thermal comfort for naturally ventilated houses in Indonesia. Energy Build. 2004, 36, 614-626. [CrossRef]

21. Nicol, F. Adaptive thermal comfort standards in the hot-humid tropics. Energy Build. 2004, 36, 628-637. [CrossRef]

22. Rangsiraka, P. Thermal Comfort in Bangkok residential buildings, Thailand. In Proceedings of the PLEA2006 23rd Conference on Passive and Low Energy Architecture, Geneva, Switzerland, 6-8 September 2006.

23. Eyre, M.; Hashemi, A.; Cruickshank, H.; Jordan, M. Transition in housing design and thermal comfort in rural Tanzania. In Proceedings of the 5th International Conference on Zero Energy Mass Custom Home (ZEMCH 2016), Kuala Lumpur, Malaysia, 20-23 December 2016.

24. Jayasinghe, M.T.; Attalage, R.A.; Jayawardena, A.I. Thermal comfort in proposed three-storey passive houses for warm humid climates. Energy Sustain. Dev. 2002, 6, 63-73. [CrossRef]

25. Alvarado, J.L.; Martínez, E. Passive cooling of cement-based roofs in tropical climates. Energy Build. 2008, 40, 358-364. [CrossRef]

26. Arayela, O. Sustainable Housing Development Policy for Developing Countries of Africa-Nigeria as a Case Study; Ural, O., Abrantes, V., Tadeu, A., Eds.; Wide Dreams Projectos Multimedia Lda: Coimbra, Portugal, 2002.

27. Cho, K.-M.; Lee, T.-G.; Han, Y.-H. A Study on Heating Energy Monitoring of a Rural Detached House Applying Passive House Design Components. J. Korea Inst. Ecol. Archit. Environ. 2013, 13, 39-46. [CrossRef]

28. Jayasinghe, M.T.; Priyanvada, A.K. Thermally comfortable passive houses for tropical uplands. Energy Sustain. Dev. 2002, 6, 45-54. [CrossRef]

29. Prianto, E.; Depecker, P. Characteristic of airflow as the effect of balcony, opening design and internal division on indoor velocity: A case study of traditional dwelling in urban living quarter in tropical humid region. Energy Build. 2002, 34, 401-409. [CrossRef]

30. Garde, F.; Boyer, H.; Gatina, J.C. Elaboration of global quality standards for natural and low energycooling in French tropical island buildings. Energy Build. 1999, 34, 71-83. [CrossRef]

31. The Concrete Centre. MPA-The Concrete Centre. Available online: http://www.concretecentre.com/about_ us.aspx (accessed on 3 August 2015).

32. Tarantola, S.; Giglioli, N.; Jesinghaus, J.; Saltelli, A. Can global sensitivity analysis steer the implementation of models for environmental assessments and decision making? Stoch. Environ. Res. Risk Assess. 2002, 16, 63-76. [CrossRef] 
33. Lomas, K.J.; Eppel, H. Sensitivity Analysis techniques for building thermal simulation programs. Energy Build. 1992, 19, 21-44. [CrossRef]

34. Hashemi, A.; Khatami, N. Effects of Solar Shading on Thermal Comfort in Low-income Tropical Housing. Energy Procedia 2017, 111, 235-244. [CrossRef]

35. Ministry of Information and Communication Technology. The Gender Statistics Survey. Available online: http:/ / web.nso.go.th/en/survey/gender/gender.htm (accessed on 29 July 2015).

36. Chartered Institution of Building Services Engineers [CIBSE]. CIBSE GUIDE A: Environmental Design; CIBSE: London, UK, 2007.

37. The Chartered Institution of Building Services Engineers. CIBSE Guide a Environmental Design; The Chartered Institution of Building Services Engineers: London, UK, 2006; Volume 7.

38. British Standards Institution [BSI]. BS EN 15251: 2007: Indoor Environmental Input Parameters for Design and Assessment of Energy Performance of Buildings Addressing Indoor Air Quality, Thermal Environment, Lighting and Acoustics; BSI: London, UK, 2007.

39. Nicol, F.; Humphreys, M. Derivation of the adaptive equations for thermal comfort in free-running buildings in European standard EN15251. Build. Environ. 2010, 45, 11-17. [CrossRef]

40. Tuohy, P.G.; Humphreys, M.A.; Nicol, F.; Rijal, H.B.; Clarke, J.A. Occupant behaviour in naturally ventilated and hybrid buildings. Am. Soc. Heat. Refrig. Air Cond. Eng. [ASHRAE] Trans. 2009, 115, 16-27.

41. Chartered Institution of Building Services Engineers [CIBSE]. CIBSE TM52: 2013: The Limits of Thermal Comfort: Avoiding Overheating in European Buildings; BSI: London, UK, 2013.

42. Telford, J.K.; Uy, M. Optimization by Design of Experiment techniques. In Proceedings of the 2009 I11 Aerospace Conference, Big Sky, MT, USA, 7-14 March 2009; pp. 1-10. Available online: http:/ /i11xplore.i11. org /xpls/abs_all.jsp?arnumber=4839625 (accessed on 20 June 2015).

43. Morris, M.D. Factorial Sampling Plans for Preliminary Computational Experiments. Technometrics 1991, 33, 167-174. [CrossRef]

44. SimLab 2.2. Simlab 2.2 Reference Manual. SimLab 2.2, 2015. Available online: https://ec.europa.eu/jrc/en/ samo/simlab (accessed on 15 May 2015).

45. Hashemi, A.; Cruickshank, H.; Cheshmehzani, A. Improving Thermal Comfort in Low-income Tropical Housing: The Case of Uganda. In Proceedings of the ZEMCH 2015 International Conference, Lecce, Italy, 22-25 September 2015; pp. 22-25.

46. Hashemi, A. Climate Resilient Low-income Tropical Housing. Energies 2016, 9, 486. [CrossRef] 